\title{
Convergent Evolution of Effector Protease Recognition by Arabidopsis and Barley
}

\author{
Morgan E. Carter, ${ }^{1}$ Matthew Helm, ${ }^{2}$ Antony V. E. Chapman, ${ }^{3,4}$ Emily Wan, ${ }^{1}$ Ana Maria Restrepo Sierra,,${ }^{1,5}$ \\ Roger W. Innes, ${ }^{2,+}$ Adam J. Bogdanove, ${ }^{1,+}$ and Roger P. Wise ${ }^{3,4,6}$ \\ ${ }^{1}$ Plant Pathology and Plant-Microbe Biology Section, School of Integrative Plant Science, Cornell University, Ithaca, NY, U.S.A.; \\ ${ }^{2}$ Department of Biology, Indiana University, Bloomington, IN, U.S.A.; ${ }^{3}$ Interdepartmental Genetics \& Genomics Graduate \\ Program and ${ }^{4}$ Department of Plant Pathology \& Microbiology, lowa State University, Ames, IA, U.S.A.; ${ }^{5}$ Facultad de Ciencias, \\ Universidad Nacional de Colombia Sede Medellín, Medellín, Colombia; and ${ }^{6}$ Corn Insects and Crop Genetics Research, \\ USDA-Agricultural Research Service, Ames, IA, U.S.A.
}

Accepted 12 November 2018.

The Pseudomonas syringae cysteine protease AvrPphB activates the Arabidopsis resistance protein RPS5 by cleaving a second host protein, PBS1. AvrPphB induces defense responses in other plant species, but the genes and mechanisms mediating AvrPphB recognition in those species have not been defined. Here, we show that AvrPphB induces defense responses in diverse barley cultivars. We also show that barley contains two PBS1 orthologs, that their products are cleaved by AvrPphB, and that the barley AvrPphB response maps to a single locus containing a nucleotide-binding leucine-rich repeat (NLR) gene, which we termed AvrPphB Response 1 (Pbr1). Transient coexpression of PBR1 with wild-type AvrPphB but not with a protease inactive mutant triggered defense responses, indicating that PBR1 detects AvrPphB protease activity. Additionally, PBR1 coimmunoprecipitated with barley and Nicotiana benthamiana PBS1 proteins, suggesting mechanistic similarity to detection by RPS5. Lastly, we determined that wheat cultivars also recognize AvrPphB protease activity and contain two putative Pbrl orthologs. Phylogenetic analyses showed, however, that PbrI is not orthologous to RPS5. Our results indicate that the ability to recognize AvrPphB evolved convergently and imply that selection to guard PBS1-like

Morgan E. Carter and Matthew Helm contributed equally to this work.

Mention of trade names or commercial products in this publication is solely for the purpose of providing specific information and does not imply recommendation or endorsement by the United States Department of Agriculture (USDA) or the National Science Foundation. USDA is an equal opportunity provider and employer.

${ }^{\dagger}$ Corresponding authors: R. W. Innes; rinnes@indiana.edu and A. J. Bogdanove; ajb7@cornell.edu

Funding: This research was supported in part by National Science Foundation-Plant Genome Research Program Division of Integrative Organismal Systems grants 1339348 (to R. P. Wise, A. J. Bogdanove, and R. W. Innes) and 1551452 (to R. W. Innes) and USDA-Agricultural Research Service project 3625-21000-060-00D (to R. P. Wise). The funders had no role in study design, data collection and analysis, decision to publish, or preparation of the manuscript.

The $\boldsymbol{e}$-Xtra logo stands for "electronic extra" and indicates that three supplementary figures and three supplementary tables are published online.

This article is in the public domain and not copyrightable. It may be freely reprinted with customary crediting of the source. The American Phytopathological Society, 2019. proteins occurs across species. Also, these results suggest that PBS1-based decoys may be used to engineer protease effector recognition-based resistance in barley and wheat.

Plant disease resistance is often mediated by intracellular innate immune receptors known as nucleotide-binding leucine-rich repeat proteins (NLRs). The primary function of NLRs is to detect the presence of pathogen-secreted effector proteins, sometimes indirectly through effector-induced modification of other host proteins (Jones and Dangl 2006). Recognition of effectors by NLRs usually activates a programmed cell death response known as the hypersensitive reaction (HR) (Coll et al. 2011; Klement and Goodman 1967). A well-studied example of an NLR that indirectly detects its cognate effector is RPS5 from Arabidopsis. RPS5 detects the Pseudomonas syringae pv. phaseolicola effector protease AvrPphB by monitoring the conformational status of an Arabidopsis substrate of AvrPphB, the serine/threonine protein kinase PBS1 (Ade et al. 2007; DeYoung et al. 2012; Qi et al. 2014; Shao et al. 2003). RPS5 forms a 'pre-activation complex' with PBS1, and, when PBS1 is cleaved by AvrPphB, the resulting conformational change is sensed by RPS5, culminating in activation of the NLR and subsequent induction of HR (Ade et al. 2007; DeYoung et al. 2012; Shao et al. 2003).

PBS1 is one of the most well-conserved defense-related genes in flowering plants, and the products of $P B S 1$ orthologs in wheat and Arabidopsis can be cleaved by AvrPphB (Caldwell and Michelmore 2009; Kim et al. 2016; Sun et al. 2017). PBS1 belongs to receptor-like cytoplasmic kinase (RLCK) family VII, which has many members with demonstrated roles in patterntriggered immunity (PTI) (DeYoung et al. 2012; Zhang et al. 2010). For example, family VII RLCKs BIK1 and PBL1 physically associate with the flagellin-detecting receptor FLS2 (Zhang et al. 2010). Of the 45 Arabidopsis proteins within RLCK family VII, nine are PBS1-like (PBL) kinases cleaved by AvrPphB (DeYoung et al. 2012; Shao et al. 2003; Zhang et al. 2010). Furthermore, AvrPphB inhibits FLS2-dependent PTI as well as defense responses triggered by EF-Tu and chitin (Zhang et al. 2010). However, only its cleavage of PBS1 activates RPS5 (Ade et al. 2007; Zhang et al. 2010).

Because of their role in PTI, RLCKs and other kinases are commonly targeted by pathogen effectors (Yamaguchi et al. 2013). Examples beyond the AvrPphB-PBS1 interaction include the RLCK BIK1, which is uridylylated by AvrAC from Xanthomonas campestris pv. campestris, and the receptor-like kinase BAK1, which is bound by the Pseudomonas syringae pv. tomato 
effectors AvrPto and AvrPtoB to inhibit signaling (Feng et al. 2012; Shan et al. 2008). Some kinases targeted by effectors appear to play little to no primary role in immunity but function as decoys, guarded by NLRs to detect effector activity. An example is the RLCK PBL2 in Arabidopsis, which is uridylylated by AvrAC like BIK1 and is guarded by the NLR ZAR1 (Wang et al. 2015).

Determining whether PBS1 orthologs are guarded in diverse plant species is of particular interest because it will provide insight into the evolution of disease resistance gene specificity and could enable engineering of new disease resistance specificities in crop plants. Kim et al. (2016) demonstrated that the AvrPphB cleavage site sequence within PBS1 can be substituted with a sequence recognized by an effector protease of another pathogen, thereby generating a synthetic PBS1 decoy. Cleavage of PBS1 decoys in planta activates RPS5-dependent HR, effectively broadening the recognition specificity of RPS5 (Kim et al. 2016). Thus, in plant species in which a PBS1 ortholog is guarded, engineering these orthologs to serve as substrates of other pathogen proteases offers an attractive approach for generating resistance tailored to pathogens of those species. Given that plant pathogenic viruses, bacteria, fungi, oomycetes, and nematodes express proteases during infection, engineering the RPS5/PBS1 surveillance system may be an effective strategy for developing resistance to many important plant diseases (Adams et al. 2005; Antonino de Souza Júnior et al. 2013; Dean 2011; Jashni et al. 2015).

While it was recently reported that bread wheat (Triticum aestivum subsp. aestivum) encodes a homolog of Arabidopsis PBS1, TaPBS1, that can be cleaved by AvrPphB, it remains unknown whether TaPBS1 is guarded, i.e., whether wheat or other cereals can recognize and respond to AvrPphB (Sun et al. 2017). Unlike the PBL kinases, NLR genes are under intense selection pressure to diversify, and they vary greatly in number and structure across plant genomes (Jacob et al. 2013). For example, grasses are missing the entire toll interleukin 1 domain-containing family of NLRs that is present in many dicots (Collier et al. 2011). However, it is plausible that proteins functionally analogous to RPS5 guard AvrPphB-cleavable PBS1 homologs in the grasses, especially given the central role that RLCK proteins play in immunity. We investigated this hypothesis using diploid barley (Hordeum vulgare subsp. vulgare) as a model because of its rich genetic resources, including a highquality genome sequence (Mascher et al. 2017) and large nested association mapping (NAM) populations (Nice et al. 2016).

Here, we show that multiple barley varieties indeed recognize and respond to AvrPphB protease activity and that barley also contains PBLs that are cleaved by AvrPphB. Using newly developed NAM resources, we mapped the AvrPphB response to a single segregating locus on chromosome $3 \mathrm{HS}$ and identified an NLR gene that we named $A v r P p h B$ response 1 ( $P b r l$ ). We confirmed that PBR1 mediates AvrPphB recognition using transient expression assays in Nicotiana benthamiana, and determined that PBR1 associates with PBS1 homologs in planta. Phylogenetic analyses indicate that Pbrl and RPS5 are not orthologous, hence the ability to recognize AvrPphB protease activity has evolved independently in monocots and dicots. Last, we show that wheat varieties also recognize AvrPphB protease activity and harbor two putative orthologs of Pbrl, suggesting that the PBS1-decoy system might be deployed in barley and in wheat.

\section{RESULTS}

\section{AvrPphB and not a catalytically inactive derivative triggers defense responses in barley.}

To test whether barley can detect AvrPphB protease activity, we delivered AvrPphB to barley leaves using $P$. syringae pv. tomato D36E, which is a derivative of strain DC3000 lacking all type III secretion system effectors (Wei et al. 2015). Seedlings were infiltrated with D36E expressing AvrPphB or the catalytically inactive mutant AvrPphB(C98S) and were scored for visible responses at 2 and 5 days postinfiltration (dpi).

We tested a diverse set of barley lines and observed a variety of responses. Representative examples are shown in Figure 1, and the complete list of cultivars and their responses are provided in Supplementary Table S1. Based on the range of responses we saw, we scored the phenotypes as no response $(\mathrm{N})$ or as one of four responses: low chlorosis (LC) indicates a weak, but noticeable response, chlorosis (C) for strong yellow, high chlorosis (HC) for a chlorotic response that gives way to cell death, and hypersensitive reaction (HR) for cell collapse and browning visible by day 2 . Of the 150 barley genotypes screened, 29 were scored as LC, 17 as C, 13 as HC, and six as HR. Both chlorotic and cell-death responses were considered defense responses, as chlorosis has been documented as a defense response in grasses, correlating with bacterial growth reduction and hydrogen peroxide accumulation (Smith and Mansfield 1981; Yin and Hulbert 2010).

\section{PBS1 homologs in barley contain}

the AvrPphB recognition site and are cleaved by AvrPphB.

Having found that many barley lines recognize $\mathrm{D} 36 \mathrm{E}$ expressing AvrPphB, we sought to determine whether barley contains a recognition system functionally analogous to the Arabidopsis RPS5-PBS1 pathway. Because PBS1 is one of the most well-conserved defense genes in flowering plants, with orthologs present in monocot and dicot crop species (Caldwell and Michelmore 2009), we first asked whether barley contains a PBS1 homolog cleavable by AvrPphB.

We used amino acid sequences from all characterized Arabidopsis PBL (AtPBL) proteins, Arabidopsis PBS1 (AtPBS1), and 20 barley PBL (HvPBL) protein sequences homologous to

\begin{tabular}{|c|c|c|c|}
\hline Line & Response & AvrPphB & C98S \\
\hline Rasmusson* & * $\quad H R$ & & $\leq$ \\
\hline Haruna Nijo & $\mathrm{HR}$ & & c \\
\hline Gorak & $\mathrm{HC}$ & & $=$ \\
\hline PI061533 & $\mathrm{HC}$ & & $<$ \\
\hline PI584977 & C & & c \\
\hline PI163409 & C & & 5 \\
\hline Clho15600* & LC & & $r$ \\
\hline Cl 16151 & LC & & - \\
\hline PI386650 & $N$ & & c \\
\hline $\mathrm{PI} 362207^{*}$ & $N$ & & 7 \\
\hline Morex & $N$ & & 2 \\
\hline PI329000* & $N$ & & 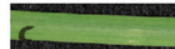 \\
\hline
\end{tabular}

Fig. 1. AvrPphB protease activity elicits a range of responses in barley lines. Representative barley leaves from 12 lines after infiltration with strains of Pseudomonas syringae pv. tomato DC3000(D36E) expressing AvrPphB or a catalytically inactive mutant, $\mathrm{AvrPphB}(\mathrm{C} 98 \mathrm{~S})$. Primary leaves of 10-dayold plants were infiltrated, using a needleless syringe, with a bacterial suspension at an optical density at $600 \mathrm{~nm}=0.5$ and were photographed at 5 days postinfiltration. Phenotypes were scored as: N, no response; LC, low chlorosis; C, chlorosis; HC, high chlorosis; and HR, hypersensitive reaction. At least six plants were infiltrated with both strains per line over two repeats. Asterisks (*) indicate parental lines of the mapping population families used for the genome-wide association study. 
AtPBS1 and AtPBL proteins to identify the barley proteins most closely related to Arabidopsis PBS1. Bayesian phylogenetic analyses showed that HORVU2Hr1G070690.2 (MLOC_13277) was the closest homolog to AtPBS1, whereas HORVU3Hr1G035810.1 (MLOC_12866) was the second most closely related (Fig. 2A; Supplementary Fig. S1). Both proteins are more similar to AtPBS1 than to other AtPBL and HvPBL proteins, indicating that the two barley genes are co-orthologous to AtPBS1. Full-length amino acid alignments showed that HORVU2Hr1G070690.2 and HORVU3Hr1G035810.1 are 66 and $64 \%$ identical to Arabidopsis PBS1, respectively (Supplementary Fig. S2). Alignment of the two barley gene products and Arabidopsis PBS1 across the kinase domain showed 86 and $79 \%$ identity, respectively. Further characterization of the HvPBS1 orthologs showed that each contains several domains that are conserved in AtPBS1, including putative N-terminal palmitoylation and myristoylation sites required for plasma membrane localization and the protease cleavage site sequence recognized by AvrPphB (Fig. 2B). We therefore designated HORVU2Hr1G070690.2 (MLOC_13277) as HvPbsl-1 (GenBank MH982439) and HORVU3Hr1G035810.1 (MLOC_12866) as HvPbsl-2 (GenBank MH982440).
Conservation of the AvrPphB cleavage site sequences within the barley PBS1 homologs led us to hypothesize that AvrPphB would cleave HvPBS1-1 and HvPBS1-2. To test this, HvPBS11 and HvPBS1-2 were fused to a three-copy human influenza hemagglutinin (3xHA) epitope tag and transiently coexpressed with AvrPphB:myc in Nicotiana benthamiana. Western blot analysis, indeed, showed that HvPBS1-1:HA and HvPBS1-2: HA are each cleaved by AvrPphB:myc (Fig. 2C). As a control, we coexpressed HvPBS1-1:HA and HvPBS1-2:HA with protease inactive AvrPphB(C98S):myc and this did not produce any cleavage products (Fig. 2C). Collectively, these data show that barley contains two PBS1 homologs whose protein products can be cleaved by AvrPphB and whose function may be analogous to AtPBS1.

\section{A single NLR gene-rich region in the barley genome is associated with AvrPphB response.}

Given the response to AvrPphB in some barley lines and the presence of conserved AvrPphB-cleavable PBS1 homologs in barley, we hypothesized that the responding barley lines contain a PBS1-guarding NLR analogous to RPS5. To identify candidates, we carried out a genome-wide association study (GWAS).

A

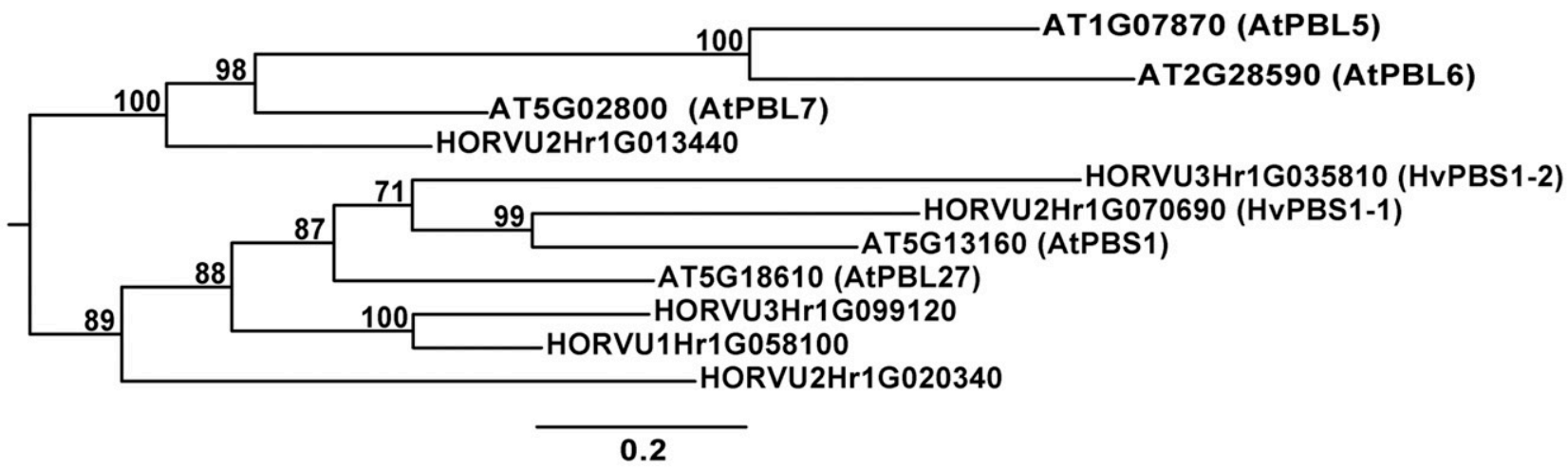

B

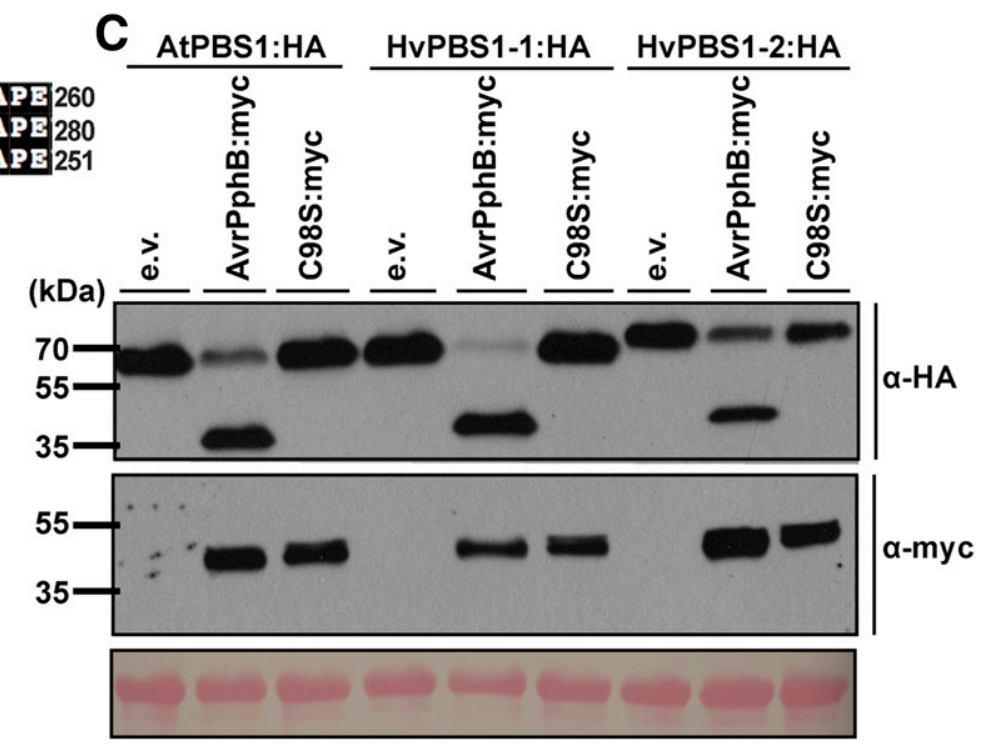

AtPBS1 231 DFGLAKLGPT TDKSHVSTRVMGTYGYCAPE 260

HVPBS1-1 251 DFGLAKL GPVGDKSEV STRVMGTY GYCAPE 280 HvPBS1-2 222 DFGLAKLGPVGDKTHVTTRVMGTYGYCAPE 251

HvPBS1-2 222 PFCLALGPVex

AvrPphB cleavage site

Fig. 2. Barley contains two PBS1 homologs that are cleaved by AvrPphB. A, HORVU2Hr1G070690.2 (HvPBS1-1) and HORVU3Hr1G035810.1 (HvPBS1-2) are co-orthologous to Arabidopsis PBS1. Shown is a Bayesian phylogenetic tree generated from the amino acid sequences of Arabidopsis PBS1 (AtPBS1) and closely related barley homologs of AtPBS1. This tree is a subset displaying the proteins most similar to AtPBS1. Branch annotations represent Bayesian posterior probabilities as a percentage. B, Alignment of the activation segment sequences of AtPBS1 and the barley PBS1 homologs. The AvrPphB cleavage site is indicated by the arrow. Numbers indicate amino acid positions. C, Cleavage of HvPBS1-1 and HvPBS1-2 by AvrPphB. Hemagglutinin (HA)-tagged barley PBS1 homologs or AtPBS1 were transiently coexpressed with or without myc-tagged AvrPphB, or a protease inactive derivative [AvrPphB(C98S)] in Nicotiana benthamiana. Six hours posttransgene induction, total protein was extracted and was immunoblotted with the indicated antibodies. Equal loading was assessed by staining the blot with Ponceau S solution (bottom). Two independent experiments were performed with similar results. 
The Rasmusson spring barley NAM population generated by BarleyCAP (A. Ollhoff and K. Smith, University of Minnesota, unpublished) contains 6,161 recombinant inbred lines (RILs) derived from crosses between the elite malting line Rasmusson and 88 diverse donor parents, each of which has associated single nucleotide polymorphism (SNP) marker data. Rasmusson, the common parent, displays a HR when infiltrated with D36E expressing AvrPphB, whereas the other parents vary in their responses (Fig. 1). For the GWAS, three NAM subpopulations (families) were chosen, two derived from nonresponding parents, i.e., PI329000 (family HR656) and PI366207 (HR658), and one from a LC-response parent, CIho15600 (HR620) (Fig. 1).

As expected for a qualitative, single gene trait, the responses segregated approximately 1:1 within each family of RILs; 39 of 73 HR656 lines, 19 of 36 HR658 lines, and 29 of 66 HR620 lines displayed a HR following infiltration with D36E expressing AvrPphB (a total of 87 of 175 RILs tested). Cosegregation of AvrPphB response with SNPs was analyzed using the R/NAM package (Xavier et al. 2015), which included 13,981 SNPs in the analysis of the 175 lines (discussed below). The GWAS identified a $22.65-\mathrm{Mb}$ region between positions 660,376,398 (SNP 3H2_266065765) and 683,030,529 (SNP 3H2_288719896) on the short arm of chromosome 3H associated with AvrPphB response (Fig. 3A). Neither $H v P b s 1-1$ nor $H v P b s 1-2$ are in this region, supporting the hypothesis that a NLR and not a PBS1 homolog is the determinant of AvrPphB response. Notably, analysis of each of the three families individually identified the same locus on chromosome $3 \mathrm{H}$ as the only significant association (Fig. 3B). The most significant SNP and the number of SNPs used in the analysis varied by population, due to the SNP variation between Rasmusson and each of the other parents.

Within the GWAS interval, there are 13 predicted NLR genes, as called by NLR-parser (Steuernagel et al. 2015) (Fig. 3A and B). In the reference genome, only four encode putative fulllength NLRs; the rest are fragments, mostly LRR domains and some partial NB-ARC domains. The most significant SNP in the analysis of all lines was S3H2_279293442 (3H:673604075; $-\log [p]=25.48)$. We selected the nearest predicted NLR to this SNP, HORVU3Hr1G107310 (3H: 672,928,614 to 672,932,121), as our top candidate for the determinant of the response to AvrPphB and tentatively named it $\mathrm{Pbrl}$ (AvrPphB response 1).

The question of whether $P b r l$ is evolutionarily related or even orthologous to RPS5 was investigated with a phylogenetic analysis of the NB-ARC domains from predicted NLR genes in the barley genome (Fig. 4). We included 15 Arabidopsis coiled coil- nucleotide binding-leucine-rich repeat (CC-NB-LRR) proteins in the analysis, including RPM1, RPP13, and RPP8, which have the most sequence similarity (in the NB-ARC) with PBR1, as determined by BLASTp. In the neighbor-joining tree in Figure 4, PBR1 is phylogenetically distant from RPS5, with many barley NLRs sharing a distinct clade with RPS5. The predicted protein product of one of the genes within the GWAS interval, HORVU3Hr1G109680 (3H: 679064240 to 679072712), did cluster with RPS5 and other Arabidopsis NLRs; we selected it as a second gene of interest and refer to it as Goi2. In terms of identity, PBR1 and RPS5 have 17\% amino acid identity in the CC domain and $29 \%$ in the NB-ARC domain, while GOI2 and RPS5 are 24 and $45 \%$ identical to each other across those domains, respectively. For comparison, PBR1 and GOI2 are 23\% identical to each other in the CC domain and $20 \%$ in the NB-ARC domain.

As a next step to identify the determinant of the AvrPphB response, we used SNP data for the entire NAM population to find additional recombinants within the 22.65-Mb GWAS interval. Based on haplotype data within the region, 18 apparent recombinants were selected from four additional families with
non-AvrPphB-responding parents and were phenotyped. Adding the genotype and phenotype data of these new lines to the GWAS increased the significance of many of the SNPs but did not narrow the interval. However, using the estimated recombination breakpoints and the phenotypes of the individual RILs to fine map the determinant of the response resulted in a 3.04-Mb region within the GWAS peak that contains $\mathrm{Pbrl}$ and no other NLR gene (Fig. 3C), supporting Pbrl rather than Goi2 as the determinant of AvrPphB recognition.

\section{Pbr1 is expressed in lines responding to}

AvrPphB and allelic variation correlates with phenotype.

The reference genome used in the GWAS is from the barley line Morex, an AvrPphB-nonresponding line (Fig. 1) (Mascher et al. 2017). Therefore, the reference genome is likely to have a nonfunctional copy of, or lack completely, the NLR hypothesized to detect AvrPphB. In the Morex genome, Pbrl is annotated as containing just a truncated NB-ARC domain and an LRR domain, missing an N-terminal domain (Marchler-Bauer and Bryant 2004). In contrast, Goi 2 encodes a full-length NLR (965 aa) with an RPS5-like CC domain (aa 27 to 66), NB-ARC domain (aa 156 to 439), and LRR (aa 537 to 864). To see if either gene sequence varies in the responding line Rasmusson, we sequenced Pbrl and Goi 2 from that line. The Rasmusson allele of Goi2 is highly similar to the Morex allele, with only three nonsynonymous mutations between them (N860I, R808H, and V282L). Among the differences between the two Pbrl sequences, we found a single nucleotide insertion in Rasmusson that restores a larger open reading frame (Fig. 5A), resulting in a predicted full-length NLR (939 aa) with an intact $\mathrm{CC}_{\mathrm{EDVID}}$ domain (aa 7 to 131), NB-ARC domain (aa 174 to 454), and an LRR domain containing 12 repeats (aa 474 to 886). For Pbrl, we will refer to the allele in Morex as Pbrl.a (GenBank MH595617) and in Rasmusson as Pbrl.b (GenBank MH595618).

Reverse transcription polymerase chain reaction (RT-PCR) was used to test the expression of Pbrl alleles in Morex and Rasmusson as well as a variety of other barley lines ranging in AvrPphB-induced responses. Pbrl was expressed in lines that respond to AvrPphB with either HR or chlorosis (Rasmusson, Haruna Nijo, PI061533, Gorak, PI584977, PI163409, CIho15600, and CI 16151) but not in nonresponding lines (PI329000, PI386650, PI362207, and Morex) (Fig. 5B). The primers used for RT-PCR were compatible with all genotypes tested, as shown by amplification from genomic DNA, and spanned an intron, to differentiate complementary DNA (cDNA) from any genomic DNA contamination. We expanded our testing to 30 total lines, 12 responders, 12 nonresponders, and six RILS from the three NAM subpopulations used for GWAS. Pbrl was expressed in all responding lines but was not expressed in nine of 12 nonresponding lines (Fig. 5B; Supplementary Fig. S3). For comparison, we assayed Goi2 expression in these lines as well and found varying levels of expression that did not correspond to AvrPphB response (Fig. 5B).

Since point mutations within an NLR can lead to changes in observable HR in planta (Stirnweis et al. 2014), we were interested to see if the responses to AvrPphB that we observed across different barley lines corresponded with sequence polymorphism at $\mathrm{Pbrl}$. We sequenced $\mathrm{Pbrl}$ alleles of 10 additional barley lines, selected at random from among the different response phenotypes (one HR, two HC, two C, two LC, and three nonresponding lines), and compared them to Pbrl.a and Pbrl.b from Morex and Rasmusson, respectively. The nucleotide sequences cluster by phenotype (Fig. 5C) when analyzed from start codon to stop codon, using the neighborjoining method. The nonresponding lines PI329000, PI386650, PI362207, and Morex have unique but similar alleles. The HR line Haruna Nijo, like Rasmusson, has the Pbrl.b allele. The 
A

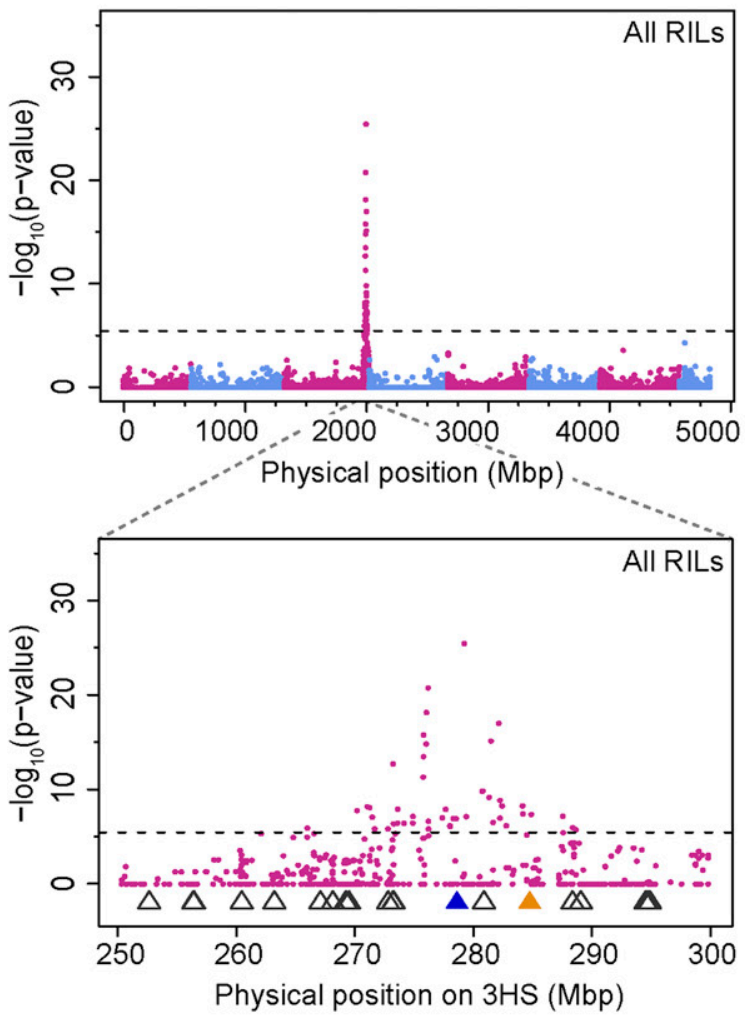

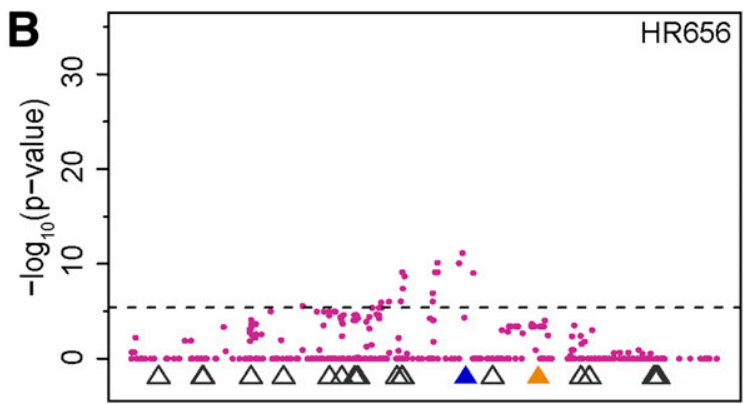
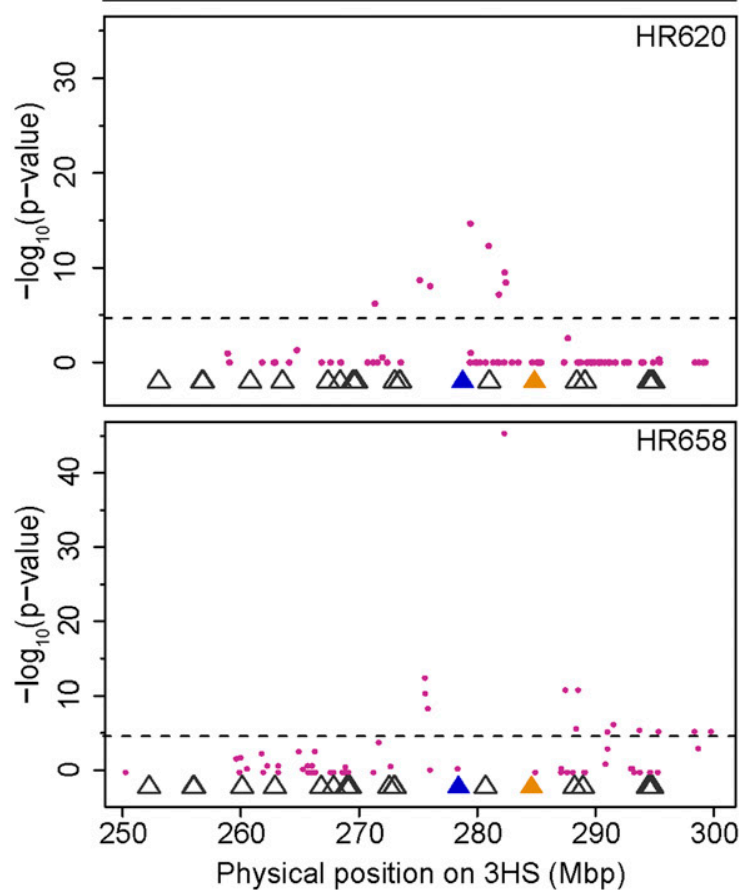

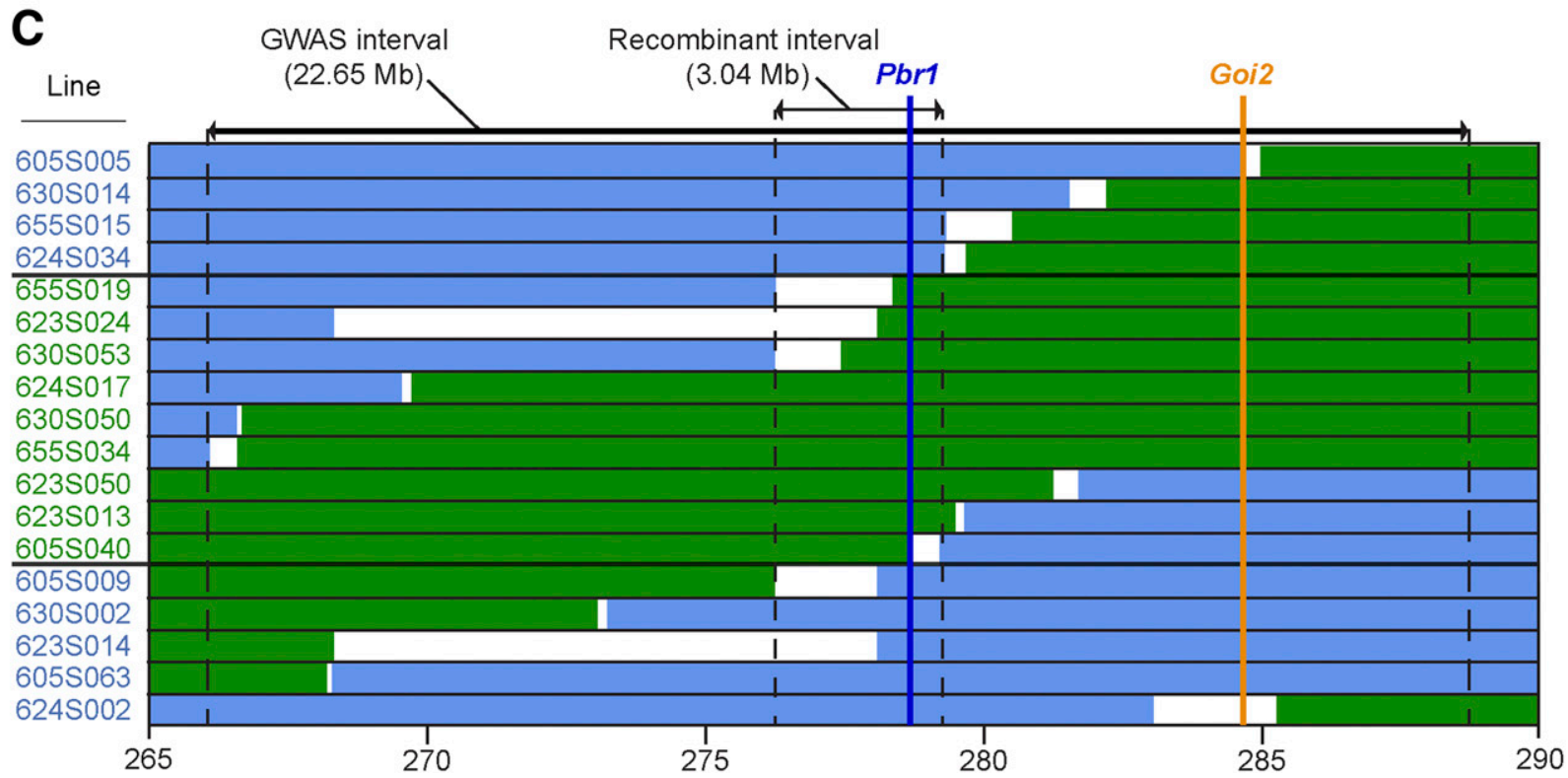

Fig. 3. Genome-wide association study identified a single locus in the barley genome significantly associated with the AvrPphB response. A, Manhattan plots of the association between single nucleotide polymorphisms (SNPs) and AvrPphB response of nested association mapping barley lines for all 175 lines from the three subpopulations and $\mathbf{B}$, the lines from each subpopulation individually (HR656, HR658, or HR620). The $x$ axis shows SNPs in the region graphed, either the whole genome or the interval containing the significant locus in the short arm of chromosome $3 \mathrm{H}(3 \mathrm{H} 2)$. The $y$ axis shows the negative logarithm of the $P$ value for the association. The locations of nucleotide-binding leucine-rich repeat (NLR) genes and NLR gene fragments predicted by NLR-parser are indicated by open triangles; the blue triangle points to Pbrl, the orange to Goi2. The dotted horizontal line indicates a false discovery rate of 0.05 with Bonferroni correction. C, Graphical representation of 18 recombinant lines from four additional families used to fine map the AvrPphB response determinant. Green indicates regions containing SNPs matching the Rasmusson genotype. Blue indicates regions matching the other parental genotype. Uncolored regions represent the intervals in which it can be concluded the recombination took place, based on the nearest flanking SNPs. Lines labeled in green font display the Rasmusson hypersensitive reaction phenotype, in blue the other parent phenotype. 


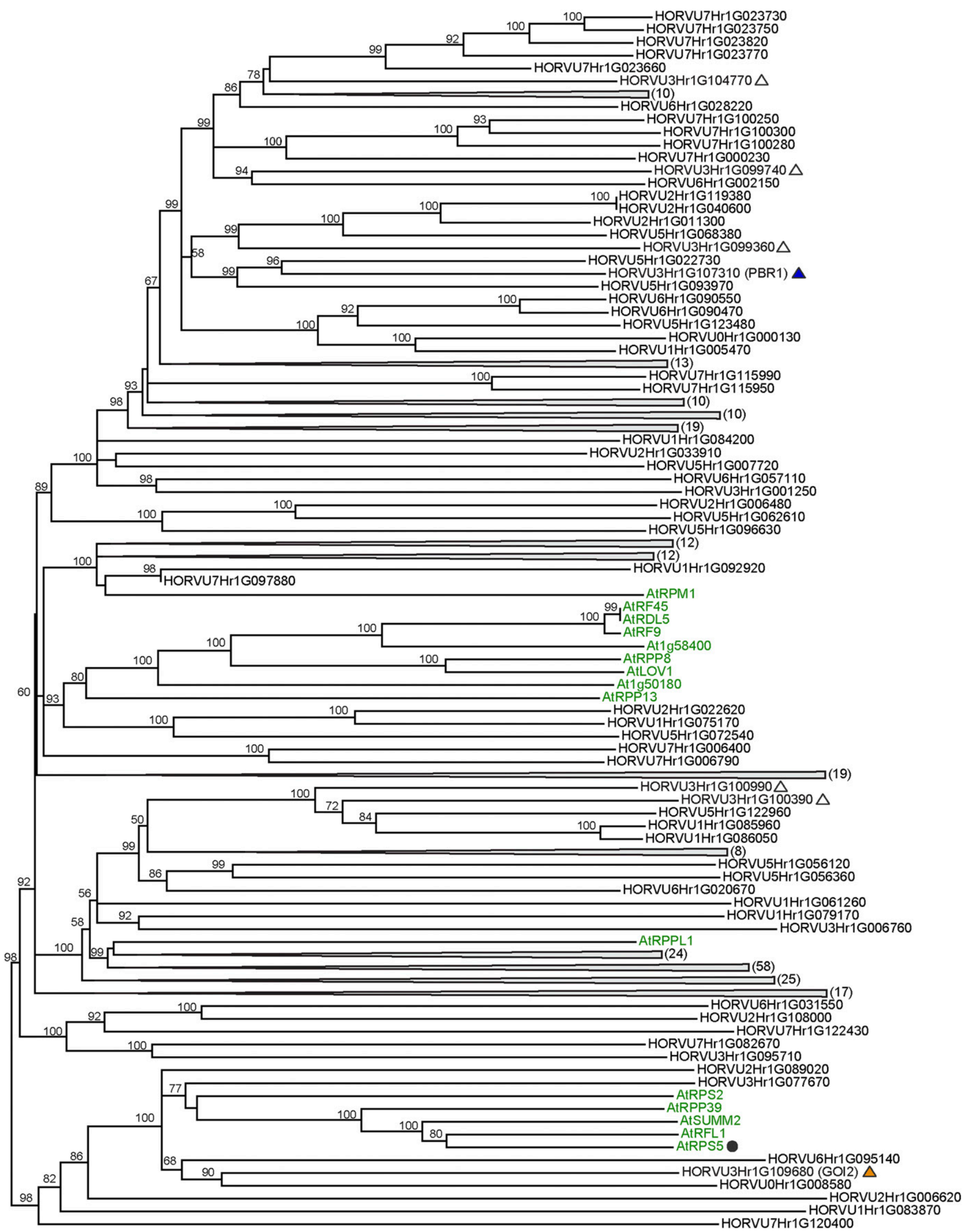

Fig. 4. RPS5 and PBR1 are phylogenetically distant. Neighbor-joining phylogenetic tree of the amino acid sequence of the NB-ARC domains from 304 nucleotide-binding leucine-rich repeat (NLR) genes predicted to be encoded in the barley genome (HORVU), and 15 known coiled-coil NLRs from Arabidopsis thaliana (At). For simplicity, clades containing more than five predicted NLRs from barley were collapsed, with the number of sequences represented in the adjacent parentheses. Node labels indicate confidence probabilities (shown for those above 50\%) from an interior-branch test with 1,000 replicates. Triangles indicate predicted protein products encoded within the genome-wide association study interval, and RPS5 is marked with a dot. 

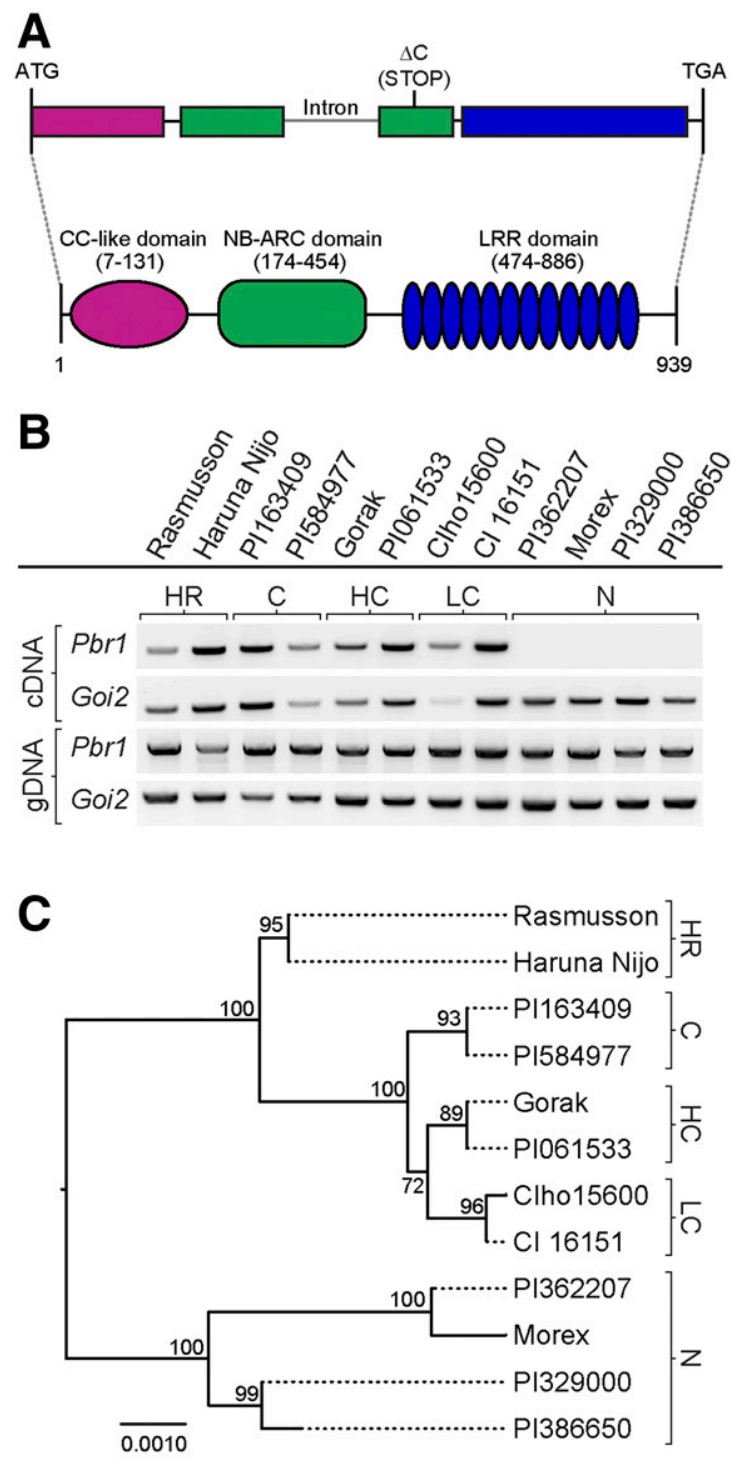

LC

D

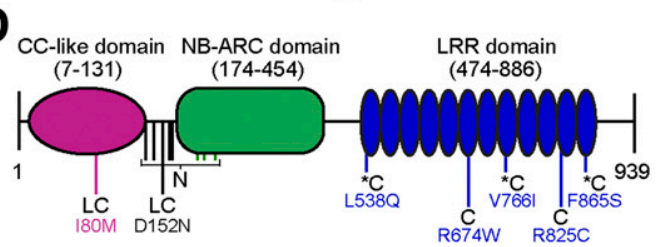

Fig. 5. Sequence and expression polymorphism in $P b r l$ across barley lines correlate to AvrPphB response. A, Schematic illustration of $P b r 1 . b$, the allele in the AvrPphB-responding line Rasmusson, showing the approximate location of a $\mathrm{C}$ nucleotide deletion that disrupts the open reading frame in Pbrl.a, the allele in the nonresponding line Morex. Below, the Pbrl.b protein product is represented, with the amino acid positions of the coiled-coil (CC), NBARC, and leucine-rich repeat (LRR) domains indicated. B, Polymerase chain reaction amplification from cDNA and genomic DNA (gDNA) of 12 representative lines that differ in their response to AvrPphB, showing expression and primer compatibility, respectively, for Pbrl and Goi2. cDNA was generated from RNA extracted from 10-day-old plants. C, A neighbor-joining tree showing the sequence relationships of $\mathrm{Pbrl}$ alleles from the barley lines represented in B and the responses of those lines to AvrPphB (on the right). The tree is based on aligned genomic DNA sequence from start codon to stop codon. Nodes are labeled with bootstrap values and the scale bar represents number of base substitutions per site. N, no response; LC, low chlorosis; C, chlorosis; HC, high chlorosis; and HR, hypersensitive reaction. D, Schematic illustration of the PBR1.b protein annotated with the approximate location of amino acid substitutions present in the predicted protein products of other Pbrl alleles and the responses of the corresponding barley lines. ${ }^{*} \mathrm{C}$ indicates a substitution present in all chlorotic response alleles.
PBR1 amino acid sequences from each of the three chlorosis response groups (LC lines CI 16151 and CIho15600, C lines PI584977 and PI163409, and HC lines Gorak and PI061533) are identical within and different across the groups; all contain three common substitutions compared with the Rasmusson allele Pbrl.b, including an L538Q substitution in the LRR (Fig. 5D). Together these observations suggest that sequence polymorphism in $\mathrm{Pbrl}$ determines response to AvrPphB.

\section{The product of $\mathrm{Pbrl}$ allele $\mathrm{Pbr} 1 . \mathrm{c}$ recognizes}

AvrPphB protease activity in $N$. benthamiana.

To directly test whether PBR1 mediates recognition of AvrPphB, we developed a transient expression assay in $N$. benthamiana. Pbrl.b from cultivar Rasmusson was cloned into a dexamethasoneinducible vector along with a C-terminal fusion to super yellow fluorescent protein (PBR1.b:sYFP). Unfortunately, transient expression of PBR1.b:sYFP alone resulted in HR with complete tissue collapse within $24 \mathrm{~h}$ of transgene induction (Fig. 6B), indicating that PBR1.b is autoactive when overexpressed in $N$. benthamiana.

To circumvent the problem posed by autoactivity of the PBR1. b protein, we tested a $\mathrm{Pbrl}$ allele from the LC line CI 16151 (Fig. 1). We designated this allele Pbrl.c (GenBank MH595619). PBR1.b and PBR1.c differ by five amino acid substitutions, of which three are located within the LRR domain (Fig. 6A). Transient expression of a PBR1.c:sYFP fusion protein in the absence of AvrPphB consistently produced a weaker HR than PBR1.b (Fig. 6B). This result allowed us to test whether the HR was enhanced in the presence of active AvrPphB.

We transiently coexpressed PBR1.c:sYFP and AvrPphB:myc in $N$. benthamiana and assessed cell death. As a control, we coexpressed AtPBS1:HA and RPS5:sYFP with AvrPphB:myc, a combination that activates cell death in $N$. benthamiana (Ade et al. 2007; DeYoung et al. 2012; Qi et al. 2014). Transient coexpression of PBR1.c:sYFP with AvrPphB:myc resulted in observable tissue collapse $24 \mathrm{~h}$ posttransgene induction, whereas coexpression of PBR1.c:sYFP with either empty vector or $\mathrm{AvrPphB}(\mathrm{C} 98 \mathrm{~S})$ :myc resulted in a much weaker celldeath response (Fig. 6C). Further, transient expression of AvrPphB:myc in the absence of PBR1.c:sYFP did not trigger $\mathrm{HR}$, indicating that the cell-death response requires PBR1.c (Fig. 6C). We performed an electrolyte leakage analysis to better quantify PBR1.c-mediated cell death. Transient coexpression of PBR1.c:sYFP with AvrPphB-myc induced greater ion leakage than PBR1.c:sYFP coexpressed with either empty vector or $\operatorname{AvrPphB}(\mathrm{C} 98 \mathrm{~S})$ :myc between 9 and $16 \mathrm{~h}$ after transgene induction, confirming that PBR1.c:sYFP recognizes and mediates a response to AvrPphB protease activity (Fig. 6D). By $26 \mathrm{~h}$ posttransgene induction, PBR1.c:sYFP expressed with $\mathrm{AvrPphB}(\mathrm{C} 98 \mathrm{~S})$ or empty vector induced ion leakage similar to that observed with coexpression of PBR1.c:sYFP and wild-type AvrPphB, indicating that PBR1.c:sYFP is weakly autoactive, consistent with the HR assays (Fig. 6D).

The observation that AvrPphB but not AvrPphB(C98S) activates PBR1.c-mediated cell death in $N$. benthamiana even in the absence of a barley PBS1 protein suggested that AvrPphB might be cleaving an $N$. benthamiana ortholog of PBS1 and that PBR1.c is recognizing that cleavage. Using a reciprocal BLAST and the amino acid sequence of Arabidopsis PBS1, we identified two orthologs of PBS1 in the allotetraploid $N$. benthamiana genome, namely, Niben101Scf02996g03008.1 and Niben101Scf04343g00001.1 (Bombarely et al. 2012), and designated them NbPbsla (GenBank MK140809) and NbPbslb (GenBank MK140810). Full-length amino acid alignment of these two proteins showed that they are $99 \%$ identical, with only a leucine to valine substitution at position 178. Importantly, both contain the AvrPphB cleavage site sequence and, thus, are 
predicted to be cleaved by AvrPphB. To test our hypothesis that, in the transient assay, PBR1.c is guarding an endogenous PBS1 ortholog, we coexpressed NbPBS1a:HA with either AvrPphB:myc or AvrPphB(C98S):myc. Consistent with our hypothesis, coexpression with AvrPphB:myc but not the protease inactive mutant resulted in cleavage of NbPBS1a:HA within $6 \mathrm{~h}$ posttransgene expression, showing that NbPBS1a: $\mathrm{HA}$ is a substrate for AvrPphB (Fig. 6E) and that its cleavage could be the trigger for PBR1.c.
PBS1 proteins immunoprecipitate with barley PBR1.c when transiently coexpressed in $N$. benthamiana.

To further test the hypothesis that PBR1.c is activated by sensing cleavage of PBS1 proteins, we performed coimmunoprecipitation analyses of PBR1.c with HvPBS1-1:HA, HvPBS1-2:HA, AtPBS1:HA, or NbPBS1a:HA. As a positive control, we coexpressed AtPBS1:HA with RPS5:sYFP, which forms a preactivation complex in the absence of AvrPphB (Ade et al. 2007). As a negative control to rule out coprecipitation of

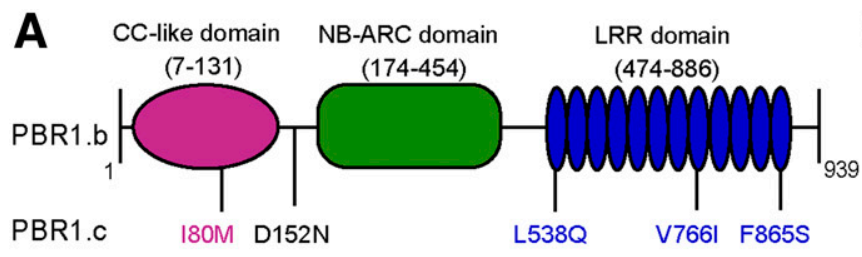

B
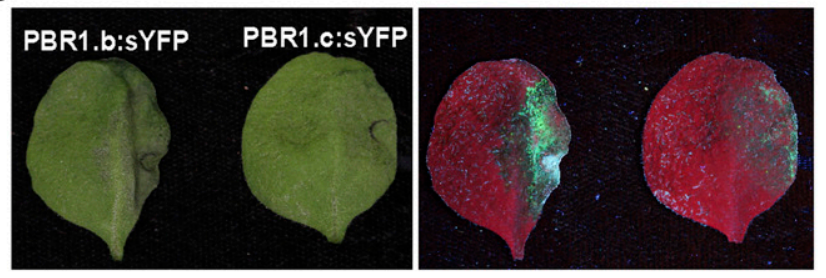

C
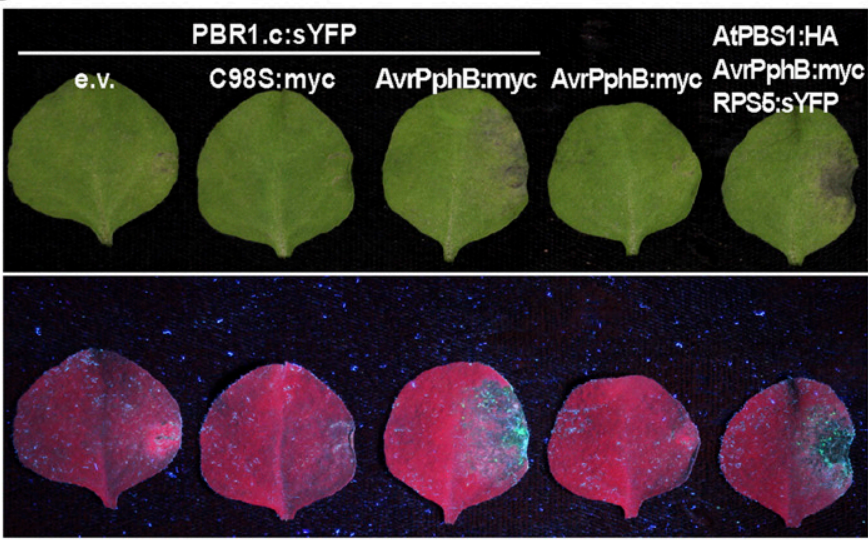

D
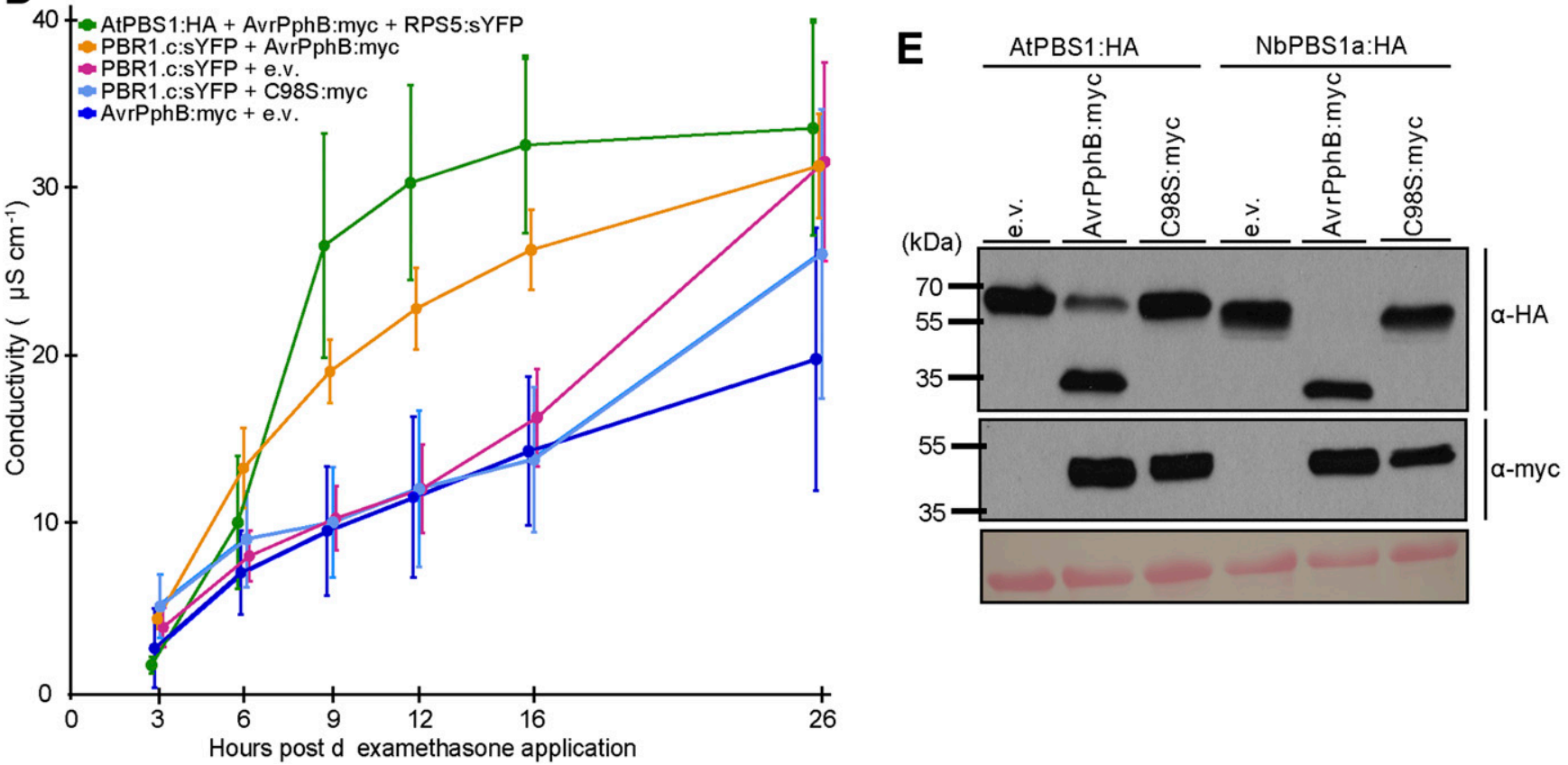

Fig. 6. Transient coexpression of PBR1.c with AvrPphB induces cell death in Nicotiana benthamiana. A, Schematic representation of the PBR1.b protein product from Rasmusson, a hypersensitive reaction (HR) line, showing the approximate locations of amino acid substitutions between the PBR1.b protein product and the PBR1.c protein product from CI 16151, a low-chlorosis line. B, Induction of cell death by PBR1.b:sYFP but not by PBR1.c:sYFP, independent of AvrPphB expression when transiently expressed in $N$. benthamiana. PBR1.b:sYFP or PBR1.c:sYFP were agroinfiltrated into 3-week-old N. benthamiana. All transgenes were under the control of a dexamethasone-inducible promoter. A representative leaf was photographed $24 \mathrm{~h}$ posttransgene induction under white and UV light. Three independent experiments were performed with similar results. C, Activation of HR by transient coexpression of PBR1.c:sYFP and AvrPphB:myc in N. benthamiana. Agroinfiltrations were used to transiently express combinations of PBR1.c:sYFP, empty vector (e.v.), AvrPphB:myc, and a protease inactive derivative, AvrPphB(C98S):myc. Hemagglutinin (HA)-tagged Arabidopsis PBS1 coexpressed with RPS5:sYFP and AvrPphB:myc was used as a positive control. All transgenes were under the control of a dexamethasone-inducible promoter. A representative leaf was photographed $24 \mathrm{~h}$ posttransgene induction under white and UV light. Three independent experiments were performed with similar results. D, Electrolyte leakage as a measure of cell death resulting from coexpression of PBR1.c:sYFP with AvrPphB:myc relative to PBR1.c:sYFP with e.v. or AvrPphB(C98S):myc. The assay was performed using $N$. benthamiana leaf discs transiently expressing the indicated combinations of constructs. Conductivity is shown as mean \pm standard deviation $(n=4)$. Three independent experiments were performed with similar results. E, Cleavage of $N$. benthamiana PBS1 (NbPBS1a) by AvrPphB. HA-tagged $N$. benthamiana PBS1 or AtPBS1 was transiently coexpressed with or without myc-tagged AvrPphB or AvrPphB(C98S) in N. benthamiana. Total protein was extracted $6 \mathrm{~h}$ posttransgene induction and was immunoblotted with the indicated antibodies. Equal loading was assessed by staining the blot with Ponceau $\mathrm{S}$ solution (bottom). Two independent experiments were performed with similar results. 
plasma membrane fragments, we transiently coexpressed the plasma membrane-localized fusion protein sYFP:LTI6b with each of the PBS1 proteins (Cutler et al. 2000). Consistent with our hypothesis, HvPBS1-1:HA, HvPBS1-2:HA, and AtPBS1:HA immunoprecipitated with PBR1.c:sYFP and not with sYFP:LTI6b, demonstrating that PBR1.c forms a complex with PBS1 proteins from barley and Arabidopsis in the absence of AvrPphB (Fig. 7). NbPBS1a:HA also immunoprecipitated with PBR1.c:sYFP (and not with sYFP: LTI6b), supporting the notion that AvrPphB-mediated cleavage of NbPBS1a activates PBR1.c-dependent $\mathrm{HR}$ in $N$. benthamiana. Though all of the PBS1 proteins immunoprecipitated with PBR1.c:sYFP, PBR1.c:sYFP preferentially associated with HvPBS1-2:HA and AtPBS1:HA (Fig. 7). Collectively, these data suggest that PBR1 forms a preactivation complex with one or more barley PBS1 orthologs, providing further evidence that PBR1 is the guard that recognizes AvrPphB activity. Importantly, CSS-PALM 4.0 predicts that PBR1.b and PBR1.c are palmitoylated at Cys314, suggesting colocalization with AvrPphB and barley PBS1 orthologs at the plasma membrane (Dowen et al. 2009; Ren et al. 2008; Sun et al. 2017).

\section{Wheat (Triticum aestivum subsp. aestivum) also recognizes} AvrPphB protease activity.

Sun et al. (2017) recently identified an ortholog of Arabidopsis PBS1 in wheat, TaPBS1, that localizes to the plasma membrane when transiently expressed in $N$. benthamiana and is cleaved by AvrPphB. However, it remained unclear whether wheat recognizes AvrPphB protease activity and would, thus, likely contain a functional analog of RPS5, such as Pbrl. We screened 34 wheat varieties obtained from the United States Department of Agriculture (USDA) Wheat Germplasm Collection for their response to D36E expressing AvrPphB (Fig. 8A; Supplementary Table S3). Twenty-nine responded with chlorosis, while five showed no visible response by 3 days postinoculation (Fig. 8A). No line responded to the protease inactive mutant AvrPphB(C98S).

To further characterize the chlorotic response in wheat, we used 3,3'-diaminobenzidine (DAB) staining to examine hydrogen peroxide accumulation following leaf infiltration with
D36E expressing either AvrPphB or AvrPphB(C98S). Consistent with the chlorotic phenotype, wheat 'Fielder' accumulated detectable hydrogen peroxide within the infiltrated area when inoculated with D36E expressing AvrPphB, whereas the mock and $\mathrm{AvrPphB}(\mathrm{C} 98 \mathrm{~S})$ treatments resulted in minimal hydrogen peroxide accumulation (Fig. 8B). In contrast, there was no significant hydrogen peroxide accumulation in wheat 'Centana' inoculated with either strain (or mock), consistent with the lack of chlorotic response of this line to AvrPphB. The correlation of chlorosis and hydrogen peroxide accumulation specifically in response to active AvrPphB is consistent with recognition in wheat associated with defense.

To examine whether this recognition in wheat might be mediated by a Pbrl ortholog, we searched the T. aestivum subsp. aestivum genome, using the Ensembl genome browser (release IWGSC RefSeq v1.0) (Clavijo et al. 2017; Kersey et al. 2018). We found TraesCS3B01G541100 (3B, 779545009 to 779548231) and TraesCS3D01G485300 (3D, 582016151 to 582019372) to be the most closely related homologs to barley Pbrl.c in wheat. TraesCS3B01G541100 and TraesCS3D01G485300 appear to be homeologous, based on their genomic locations. Full-length amino acid alignment between TraesCS3B01G541100 and TraesCS3D01G485300 showed 97\% amino acid identity. We, therefore, designated TraesCS3B01G541100 as TaPbrl-B3 and TraesCS3D01G485300 as TaPbrl-D3. TaPbrl-B3 is located on wheat chromosome $3 \mathrm{~B}$ in a position syntenic with barley $\mathrm{Pbrl}$ and encodes an NLR consisting of a predicted Rx-like CC domain (aa 7 to 131), a NB domain (aa 174 to 454), and a LRR domain (aa 474 to 886) (Fig. 8C). Full-length amino acid sequence alignment of barley PBR1.c and TaPBR1-B3 shows 93\% amino acid identity (Fig. 8C). Further, TaPBR1-B3, like barley PBR1, is predicted to be palmitoylated at Cys314, suggesting colocalization with AvrPphB and wheat PBS1. It thus seems likely that TaPBR1-B3 functions as the cognate NLR protein that mediates recognition of $\mathrm{AvrPphB}$ protease activity in wheat.

\section{DISCUSSION}

Recognition of the $P$. syringae AvrPphB protease by the Arabidopsis RPS5 NLR protein is a well-characterized example of indirect effector recognition (Kim et al. 2016). Though
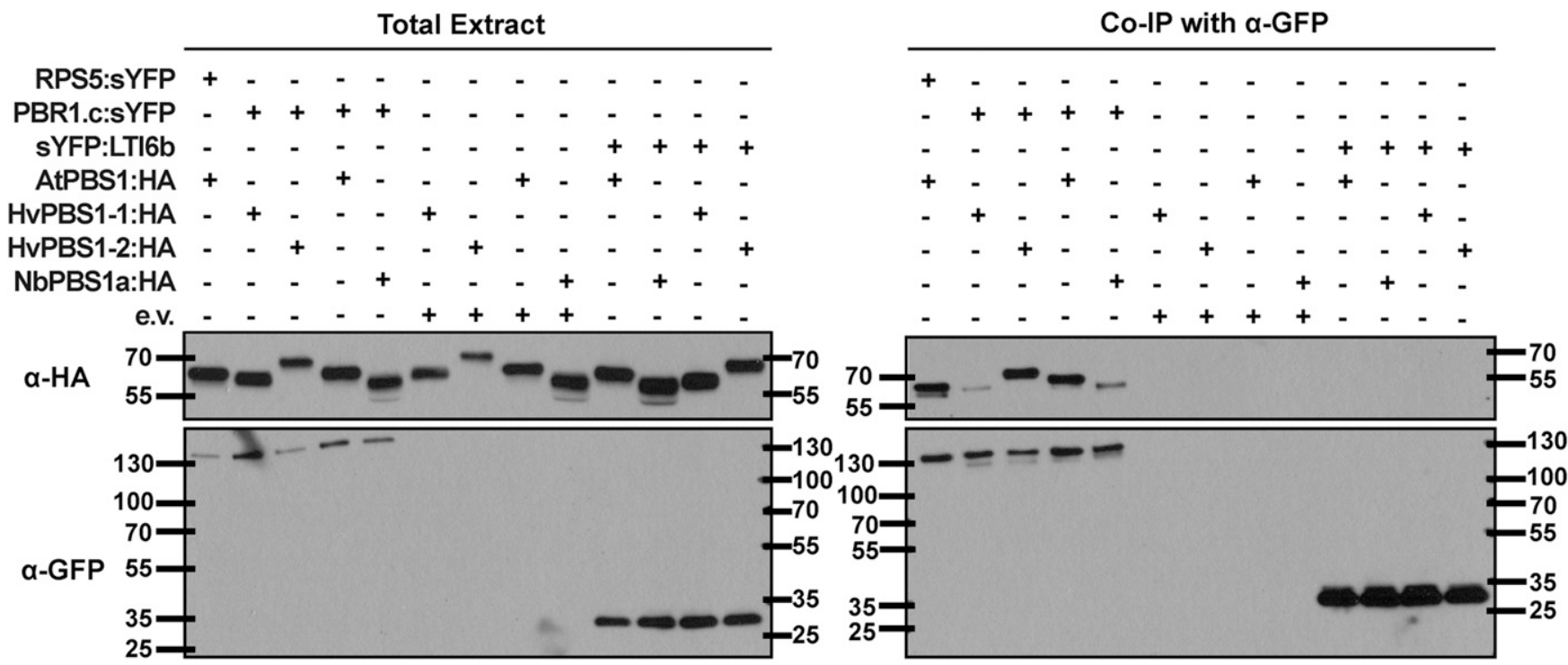

Fig. 7. PBS1 proteins immunoprecipitate with PBR1.c when transiently coexpressed in Nicotiana benthamiana. The indicated construct combinations were transiently coexpressed, in leaves of 3-week-old $N$. benthamiana plants, using agroinfiltration. All transgenes were under the control of a dexamethasoneinducible promoter. Total protein was extracted $6 \mathrm{~h}$ posttransgene induction. Hemagglutinin (HA)-tagged Arabidopsis PBS1 coexpressed with RPS5:sYFP was used as a positive control. The sYFP:LTI6b fusion protein, which is targeted to the plasma membrane (Cutler et al. 2000), was coexpressed with the HA-tagged PBS1 proteins as a negative control. Results are representative of two independent experiments. 
AvrPphB is recognized by other plant species such as soybean and common bean, the disease-resistance genes responsible for recognition outside of Arabidopsis have not been cloned and the underlying molecular mechanisms are unknown (Jenner et al. 1991; Russell et al. 2015). The evidence herein supports the conclusion that barley and Arabidopsis have convergently evolved NLRs able to detect effectors that structurally modify PBL kinases; barley cultivars respond to AvrPphB but not to a protease inactive mutant of AvrPphB, barley contains an NLR gene evolutionarily distinct from RPS5 that mediates a strong HR when coexpressed with $\operatorname{avrPphB}$ in $N$. benthamiana, and AvrPphB associates with and cleaves PBS1 orthologs from monocots and dicots.

While AvrPphB is not known to be present in any pathogens of barley, it is a member of a family of proteases present in many phytopathogenic bacteria (Dowen et al. 2009; Shao et al. 2002). More generally, proteases that target host proteins are found in many, diverse types of pathogens, and we expect conserved kinases that are involved in PTI to be common effector targets (Xia 2004). Though the functional roles of HvPBS1-1 and HvPBS1-2 as well as other barley PBL proteins are unknown, given their conservation in many flowering plant families, we can predict that they have a role in PTI signaling, as observed in Arabidopsis (Zhang et al. 2010). Our evidence supports the hypothesis that barley deploys an effector protease recognition mechanism similar to that of recognition of AvrPphB by Arabidopsis RPS5, wherein barley PBR1 guards RLCKs, such as HvPBS1-1 and HvPBS1-2, such that it is activated upon their cleavage. Within Arabidopsis populations, RPS5 is maintained as a balanced presence or absence polymorphism despite inconsistent interaction with Pseudomonas strains expressing AvrPphB homologs, suggesting other effectors are also imposing selection pressure (Karasov et al. 2014; Tian et al. 2002). How many and which effectors from barley pathogens target RLCKs is unknown.

The convergent evolution of the shared ability of PBR 1 and RPS5 to recognize AvrPphB aligns with the prediction that RLCKs that function in plant immunity are common targets of pathogen effectors and that selection to guard these proteins is ancient and widespread. A similar example of convergent evolution of NLR specificity has been described for the RPM1 and Rpg1b/Rpg1r proteins of Arabidopsis and soybean, all three of which detect effector-induced modifications of RIN4 proteins (Ashfield et al. 2004, 2014; Selote and Kachroo 2010).

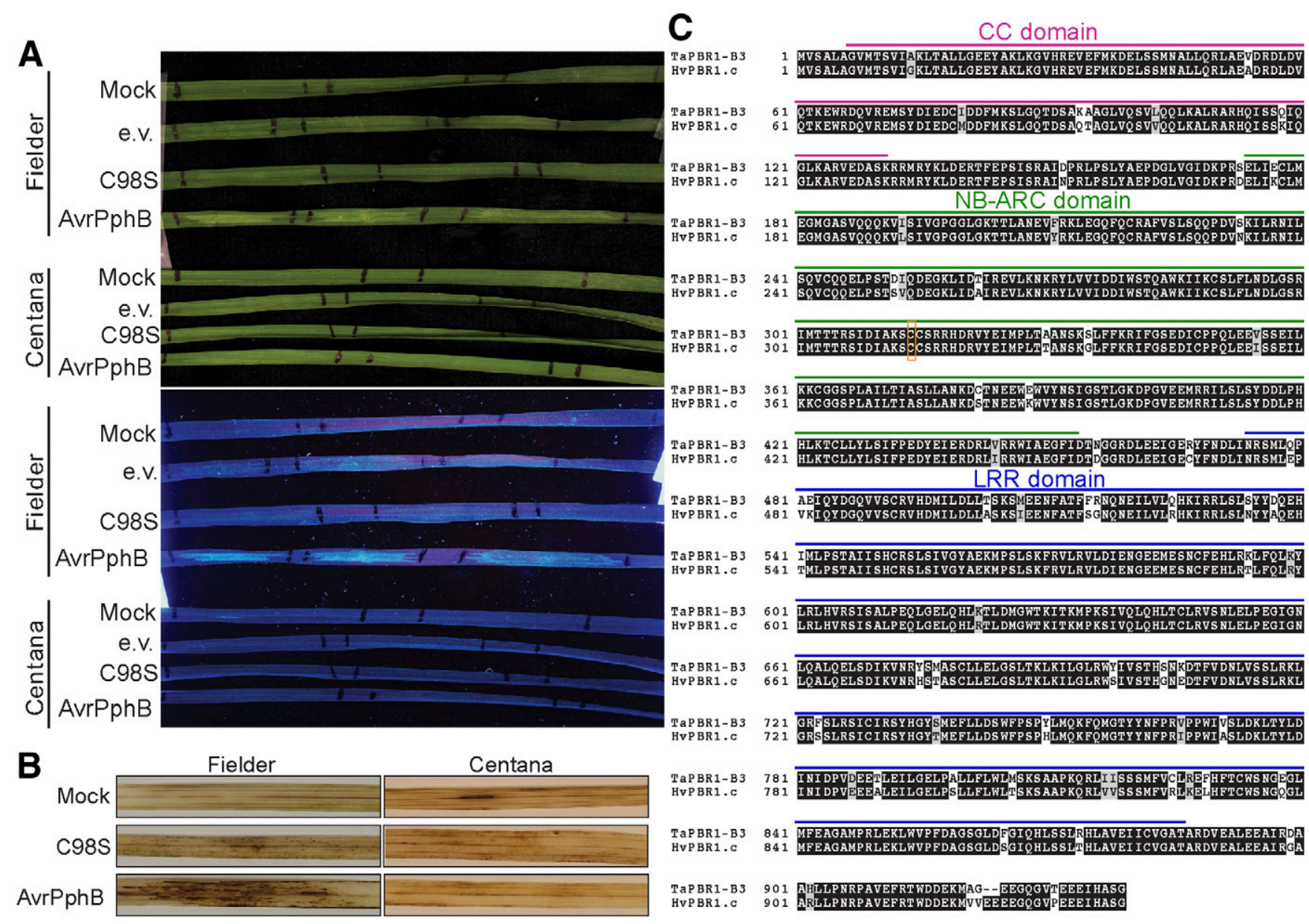

Fig. 8. Recognition of AvrPphB protease activity is conserved in wheat. A, Responses of wheat cultivars Fielder and Centana infiltrated with (top to bottom) $10 \mathrm{mM} \mathrm{MgCl}_{2}$ (mock), Pseudomonas syringae DC3000(D36E) expressing empty vector (e.v.), AvrPphB(C98S), or AvrPphB, 3 days postinfiltration (dpi), photographed under white and UV light. Bacteria (optical density at $600 \mathrm{~nm}=0.5$ ) were infiltrated into the adaxial surface of the second leaf of two-week-old seedlings. Three independent experiments were performed with similar results. B, Hydrogen peroxide accumulation. Cultivars and treatments assayed were as in panel A. At 3 dpi, leaf segments were excised from the infiltrated regions, were stained with 3,3'-diaminobenzidine solution, were cleared with $70 \%$ ethanol, and were photographed under white light. This experiment was repeated twice with similar results. C, Full-length amino acid sequence alignment between barley PBR1.c and the most closely related homolog in wheat, TraesCS3B01G541100 (TaPBR1-B3). Conserved residues and conservative substitutions are highlighted with black and gray backgrounds, respectively. The predicted coiled-coil (CC), nucleotide binding (NB-ARC), and leucine-rich repeat (LRR) domains of TaPBR1 are indicated by pink, green, and blue bars, respectively. The predicted palmitoylation site is indicated by an orange box. 
Like PBL proteins, RIN4 is targeted by multiple effectors, consistent with these proteins serving critical functions in plant immunity (Afzal et al. 2013). It is especially interesting that PBR1 and RPS5 independently evolved to detect PBL cleavage instead of directly interacting with AvrPphB or integrating a PBL decoy. Direct interaction limits the number of effectors a single NLR can detect, while guarding a commonly targeted host protein expands the response spectrum, thus allowing the NLR to detect multiple pathogen effectors. The guarding strategy might impose purifying selection on RLCKs themselves or selection to integrate an RLCK decoy into an NLR; either would reduce the risk of any guard-guardee genetic mismatch that might lead to hybrid necrosis. However, there is no obvious reason why PBR1 and RPS5 would both have each evolved to guard PBS1 rather than distinct AvrPphB substrates, and our current data do not rule out the possibility that, in barley, PBR1 is activated by cleavage of one or more different RLCKs.

When assessing the functional role of PBR1.c in AvrPphB recognition, we showed that its coexpression with AvrPphB elicited cell death in $N$. benthamiana even in the absence of barley PBS1 expression. Given that PBR1.c does not contain the AvrPphB cleavage site sequence, it is likely PBR1.c is sensing AvrPphB-mediated cleavage of an endogenous N. benthamiana PBL protein, and we showed that the PBS1 ortholog NbPBS1a, indeed, associates with PBR1 in the absence of AvrPphB and is cleaved by AvrPphB. This was true also of AtPBS1 and the barley PBS orthologs HvPBS1-1 and HvPBS1-2. Taken together, these data strongly suggest that, in barley, PBR1.c detects AvrPphB protease activity by sensing cleavage of a PBS1 protein, analogous to AvrPphB detection by RPS5. In recent work, we have attempted to test directly whether PBR1.c requires a PBS1 protein for AvrPphB recognition by silencing $N b P b s l a$ and $N b P b s l b$ (with a single hairpin construct) in the $N$. benthamiana assay. Despite knockdown of both genes, we have observed no significant reduction in PBR1.c-mediated cell death (by electrolyte leakage assay). It is possible that residual expression of $N b P b s l a$ and $N b P b s l b$ was sufficient or that, indeed, other PBL kinases in N. benthamiana that are predicted to be cleaved by AvrPphB interact with PBR1. The latter possibility is supported by our observation that PBR1 associates with PBS1 homologs from multiple plants.

$\mathrm{Pbrl}$ is expressed in the 12 tested barley lines that respond to AvrPphB and in only three of 12 lines that do not respond. The sequence polymorphisms found in $\mathrm{Pbrl}$ alleles across the 12 responding barley lines correlate with the presence and severity of the AvrPphB response (i.e., chlorosis versus strong HR). These data suggest that mutations within the Pbrl coding sequence impact the macroscopic phenotype observed when AvrPphB is present. Mutagenesis screens of specific NLRs have been shown to modify the severity of phenotype and specificity of interaction (Farnham and Baulcombe 2006; Harris et al. 2013; Segretin et al. 2014). Natural examples of the effect of single or few mutations impacting NLR function include the Pi-ta NLR in Oryzae spp., in which a single amino acid is highly correlated to resistance, and the barley Mla locus, which encodes alleles with over $90 \%$ amino acid sequence identity, that recognize different effector proteins (Huang et al. 2008; Lu et al. 2016). In wheat, alleles of the Pm3 gene have very little sequence diversity but differ in their resistance contribution to diverse Blumeria graminis f. sp. tritici isolates (Brunner et al. 2010; Stirnweis et al. 2014). Furthermore, the $P m 3 f$ allele can be modified to produce a faster, more intense HR, when expressed in $N$. benthamiana, by mutating two residues to match the $P m 3 a / P m 3 b$ alleles, which also expands the resistance spectrum of $P m 3 f$ (Stirnweis et al. 2014). These residues are in the ARC2 subdomain and do not affect protein stability but may affect signaling, sensitivity of the NLR, or interaction with a guarded host protein (Brunner et al. 2010; Stirnweis et al. 2014). We have not yet functionally characterized the polymorphisms in PBR1 to determine which, if any, modify the response to AvrPphB or if any impact specificity. However, the difference in autoactivity between PBR1.b and PBR1.c when expressed in $N$. benthamiana is further evidence that sequence polymorphism contributes to phenotype, as seen in the wheat $P m 3$ alleles.

The evidence that PBR1 is activated by cleavage of a PBS1 or PBL protein suggests that PBS1-based decoys can be used to expand protease effector recognition in barley. Barley powdery mildew (Blumeria graminis f. sp. hordei) and Wheat streak mosaic virus (WSMV) are two barley pathogens known to deploy proteases as part of the infection process (Pliego et al. 2013; Singh et al. 2018). BEC1019 is a putative metalloprotease made by B. graminis f. sp. hordei and is conserved among ascomycete fungi (Pliego et al. 2013; Whigham et al. 2015). Notably, silencing of BEC1019 by both Barley stripe mosaic virus - and single cell RNAi-based methods reduces $B$. graminis f. sp. hordei virulence, suggesting BEC1019 is secreted and required for $B$. graminis $\mathrm{f}$. sp. hordei pathogenicity (Pliego et al. 2013; Whigham et al. 2015). Similar to other potyviruses, WSMV expresses a protease, designated the nuclear inclusion antigen (NIa), that is essential for viral replication and for proper temporal expression of potyviral genes in planta (Singh et al. 2018). Importantly, the cleavage site sequence recognized by the NIa protease has been identified (Choi et al. 2000; Tatineni et al. 2011). Insertion of the BEC1019 or NIa protease cleavage site sequence into the barley PBS1 proteins should enable recognition of these proteases by PBR1. This approach could also be extended into wheat given that PBR1 and PBS1 are conserved.

\section{MATERIALS AND METHODS}

\section{Plant material and growth conditions.}

Barley seeds were planted in Cornell mix soil (1.2 cubic yards of mix contains 10.6 cubic feet of compressed peat moss, $20 \mathrm{lb}$ of dolomitric limestone, $6 \mathrm{lb}$ of $11-5-11$ fertilizer, 12 cubic $\mathrm{ft}$ of vermiculite) in plastic pots. Barley plants were grown in a growth room on a 16-h light and 8-h dark cycle with cool white fluorescent lights ( 85 to $112 \mu \mathrm{mol} / \mathrm{m}^{2} / \mathrm{s}$ at soil level) at $22^{\circ} \mathrm{C}$. Plants were watered as needed to keep soil damp.

$N$. benthamiana seeds were sown in plastic pots containing Pro-Mix B Biofungicide potting mix supplemented with Osmocote slow-release fertilizer (14-14-14) and were grown under a 12-h photoperiod at $22^{\circ} \mathrm{C}$ in growth rooms with average light intensities at plant height of 150 microEinsteins $/ \mathrm{m}^{2} / \mathrm{s}$.

Seed for wheat (Triticum aestivum subsp. aestivum) cultivars were ordered from the USDA wheat germplasm collection via the National Plant Germplasm System web portal or provided by S. Hulbert (Washington State University, Pullman, WA, U.S.A.). Wheat plants were grown in clay pots containing Pro-Mix B Biofungicide potting mix supplemented with Osmocote slow-release fertilizer (14-14-14) and were grown under a 12 -h photoperiod at $22^{\circ} \mathrm{C}$ in growth rooms with average light intensities, at plant height of 150 microEinsteins $/ \mathrm{m}^{2} / \mathrm{s}$.

\section{$P$ syringae $\mathrm{DC3000}(\mathrm{D} 36 \mathrm{E})$ in planta assays.}

Previously generated plasmids pVSP61-AvrPphB and pVSP61-AvrPphB(C98S) (a catalytically inactive mutant) (Shao et al. 2003; Simonich and Innes 1995) were each transformed into D36E, a strain of Pseudomonas syringae pv. tomato DC3000 with 36 effectors removed (Wei et al. 2015). Bacteria were grown on King's B media, supplemented with $50 \mu \mathrm{g}$ of kanamycin per milliliter, for 2 days at $28^{\circ} \mathrm{C}$, then, were 
suspended in $10 \mathrm{mM} \mathrm{MgCl}$ to an optical density at $600 \mathrm{~nm}$ $\left(\mathrm{OD}_{600}\right)$ of 0.5 . Suspensions were infiltrated into the underside of the primary leaf of 10-day-old barley seedlings by needleless syringe. Each leaf was infiltrated with bacteria expressing AvrPphB and bacteria expressing $\operatorname{AvrPphB}(\mathrm{C} 98 \mathrm{~S})$, and the infiltrated areas were marked with permanent marker. Infiltrated leaves were checked for cell collapse $2 \mathrm{dpi}$, then, were photographed and phenotyped for chlorosis and necrosis $5 \mathrm{dpi}$.

For wheat inoculations, bacteria were grown and prepared in the same way, but the adaxial side of the second leaf of 14-dayold wheat seedlings was infiltrated at three spots with one of the strains of bacteria per leaf. Responses were photographed 3 dpi, using a high-intensity long-wave $(365 \mathrm{~nm})$ ultraviolet lamp (Black-Ray B-100AP, UVP).

\section{Phylogenetic analyses.}

Sequence similarity searches were performed, using BLASTp, to gather barley amino acid sequences homologous to Arabidopsis PBS1 and PBL proteins. First, AtPBL (1 to 27), BIK1, and other PBS1-homologous sequences were gathered by searching the Arabidopsis genome (TAIR10, GCA_000001735.1) with the AtPBS1 (OAO91748.1) amino acid sequence and by name search. Potential barley PBLs were collected by searching the barley protein database (assembly Hv_IBSC_PGSB_v2) with each Arabidopsis homolog and taking the top five hits derived from distinct genes. Amino acid sequences were aligned with Clustal Omega (Sievers et al. 2011), and the alignment can be found on figshare (doi: 10.6084/m9.figshare.7318520). Bayesian phylogenetic trees were generated for the collected sequences using the program MrBayes under a mixed amino acid model (Ronquist et al. 2012). Parameters for the Markov chain Monte Carlo method were: nruns $=2$, nchains $=2$, diagnfreq $=1000$, diagnstat $=$ maxstddev. The number of generations (ngen) was initially set at 200,000 and increased by 100,000 until the maximum standard deviation of split frequencies was below 0.01 or until it was below 0.05 after $1,000,000$ generations. Phylogenetic trees were visualized in FigTree v1.4.3.

For the analysis of the barley and Arabidopsis NLRs, barley NLR genes for the entire Morex genome were predicted by NLR-parser, using the high-confidence protein predictions (Mascher et al. 2017; Steuernagel et al. 2015). The amino acid sequence of NB-ARC domains identified in this pipeline were extracted into a FASTA file, to which the NB-ARC domains from 15 Arabidopsis CC-NB-LRRs were added from UniProt accessions. The combined 319 sequences were aligned using Clustal Omega (figshare doi: 10.6084/m9.figshare.7315682), and a phylogenetic tree was constructed, using the neighborjoining p-distance method in MEGA7, with pairwise deletions (Kumar et al. 2016; Sievers et al. 2011). An interior-branch test with 1,000 bootstrap replications was used to determine the confidence probability that each branch had a length greater than zero. Clades containing more than five NLRs from barley, none of which were encoded in the GWAS interval, were collapsed, when visualized in FigTree v1.4.3, to simplify the final tree.

For the analysis of $\mathrm{Pbrl}$ alleles, nucleotide sequences were selected from each sequenced allele that spanned from the start codon to the stop codon of the Rasmusson allele, including the intron. Sequences were aligned with Clustal Omega (figshare doi: $10.6084 / \mathrm{m} 9$.figshare.7315655) and were then used to construct neighbor-joining trees in MEGA7 with the default parameters, including nucleotide substitutions type with a number of differences model, but with pairwise deletions (Kumar et al. 2016; Sievers et al. 2011). A bootstrap test of 1,000 replicates was applied.
GWAS.

The University of Minnesota spring barley NAM population comprises 6,161 RILs generated from the variety Rasmusson crossed to 88 diverse parents that represent $99.7 \%$ of captured SNP diversity. In total, approximately 24,000 SNPs were generated through use of genotyping by sequencing and the barley iSelect 9K SNP chip. The 89 parental lines were assayed for AvrPphB response as part of the initial survey of barley lines. Because the common parent, Rasmusson, displayed a strong hypersensitive response, NAM families derived from Rasmusson and a parent showing no response were chosen for GWAS.

Plants were assayed as described above, using infiltrations of two Pseudomonas strains expressing either AvrPphB or AvrPphB(C98S). Phenotypes for at least six plants of each RIL were recorded as 0 (no response or LC) or 1 (hypersensitive reaction), depending on the parental phenotype they exhibited. Lines that showed phenotypic segregation between individuals were not included in the analysis.

Genome-wide association analysis was performed with the gwas2 function from the R/NAM package, which uses an empirical Bayesian framework to determine likelihood ratios for each marker (Xavier et al. 2015). Lines from each family were identified within a family vector to account for population stratification. Markers with a minor allele frequency below 0.05 or missing data of more than $20 \%$ were removed, using the snpQC function prior to analysis. A threshold of 0.05 for the false discovery rate was used to identify significant associations. NLR-encoding gene prediction was generated using NLR-parser (Steuernagel et al. 2015) and the high confidence Morex barley genome protein predictions (Mascher et al. 2017).

For genetic fine-mapping, 18 additional RILs with recombination events in the GWAS interval were selected from other families that also had an AvrPphB-nonresponding parent. To determine which RILs to select, we subset the master SNP file by family and removed SNPs that were not variable between Rasmusson and the other parent. For visualization, SNPs that did not match neighboring markers across RILs were assumed to be miscalls and were also removed; while these could indicate double recombination events, the probability for a double recombination occurring within the $22.65 \mathrm{Mb}$ interval is 0.001 and would be even less between two or three SNPs.

\section{Construction of transgene expression plasmids.}

The AvrPphB:myc, AvrPphB(C98S):myc, RPS5:sYFP, and AtPBS1:HA constructs have been described previously (Ade et al. 2007; DeYoung et al. 2012; Shao et al. 2003). HORVU2Hr1G070690 (HvPbs 1-1) and HORVU3Hr1G035810 (HvPbs 1-2) were PCR amplified from barley accession CI 16151 (Manchuria background) and Rasmusson cDNA, respectively. The resulting fragments were gel-purified, using the QIAquick gel extraction kit (Qiagen) and were cloned into the Gateway entry vector $\mathrm{pCR} 8 / \mathrm{GW} / \mathrm{TOPO}$ (Invitrogen) to generate pCR8/GW/TOPO:HORVU2Hr1G070690 and pCR8/ GW/TOPO:HORVU3Hr1G035810, which we then designated pCR8/GW/TOPO:HvPbs1-1 and pCR8/GW/TOPO:HvPbsl-2, respectively.

The following genes were PCR-amplified with attBcontaining primers from the corresponding templates: $\mathrm{HvPbs} 1$ 1 from pCR8/GW/TOPO:HvPbs1-1, HvPbs1-2 from pCR8/ GW/TOPO:HvPbs1-2, Pbrl.b (HORVU3Hr1G107310) and Goi2 (HORVU3Hr1G109680) from Rasmusson cDNA, Pbrl.c from CI 16151 genomic DNA [gDNA], LTI6b from Arabidopsis thaliana gDNA (Col-0), and NbPbsla (Niben101Scf02996g03008.1) from Nicotiana benthamiana cDNA. The resulting PCR products were gel-purified, using the QIAquick gel extraction kit (Qiagen) or the Monarch DNA gel extraction kit (NEB) and were recombined into the Gateway donor vectors 
pBSDONR(P1-P4) or pBSDONR(P4r-P2), using the BP Clonase II kit (Invitrogen) (Qi et al. 2012). The resulting constructs were sequence-verified to check for proper sequence and reading frame.

To generate protein fusions with the desired C-terminal epitope tags, pBSDONR(P1-P4):HvPbs1-1, pBSDONR(P1$\mathrm{P} 4): H v P b s 1-2$, and pBSDONR(P1-P4):NbPbsla were mixed with the pBSDONR(P4r-P2):3xHA construct and the Gatewaycompatible expression vector pBAV154 in a 2:2:1 molar ratio. A derivative of the destination vector pTA7001, pBAV154, carries the dexamethasone-inducible promoter (Aoyama and Chua 1997; Vinatzer et al. 2006). The pBSDONR(P1-P4):Pbrl. $b$ and pBSDONR(P1-P4):Pbrl.c constructs were mixed with the pBSDONR(P4r-P2):sYFP construct and pBAV154 in a 2:2:1 molar ratio. The pBSDONR(P4r-P2):sYFP and pBSDONR (P4r-P2):3xHA constructs have been described previously (Qi et al. 2012). To generate the sYFP:LTI6b fusion protein, the pBSDONR(P4r-P2):LTI6b construct was mixed with the pBSDONR(P1-P4):sYFP construct and pBAV154 in a 2:2:1 molar ratio. Plasmids were recombined by the addition of LR Clonase II (Invitrogen) and were incubated overnight at $25^{\circ} \mathrm{C}$, following the manufacturer instructions. Constructs were sequence verified and were subsequently used for transient expression assays in $N$. benthamiana.

\section{Transient expression assays in $N$. benthamiana.}

For transient expression assays in $N$. benthamiana, we followed the protocol described by DeYoung et al. (2012) and Kim et al. (2016). Briefly, the dexamethasone-inducible constructs were transformed into Agrobacterium tumefaciens GV3101 (pMP90) strains and were streaked onto Luria-Bertani (LB) plates containing $30 \mu \mathrm{g}$ of gentamicin sulfate and $50 \mu \mathrm{g}$ of kanamycin per milliliter. Cultures were prepared in liquid LB media $(5 \mathrm{ml})$ supplemented with $30 \mu \mathrm{g}$ of gentamicin and $50 \mu \mathrm{g}$ of kanamycin per milliliter and were shaken overnight at $30^{\circ} \mathrm{C}$ and $250 \mathrm{rpm}$ on a New Brunswick orbital shaker. After overnight culture, the bacterial cells were pelleted by centrifuging at $3,000 \times g$ for $3 \mathrm{~min}$ and were resuspended in $10 \mathrm{mM} \mathrm{MgCl}_{2}$ supplemented with $100 \mu \mathrm{M}$ acetosyringone (Sigma-Aldrich). The bacterial suspensions were adjusted to an $\mathrm{OD}_{600}$ of 0.9 for $\mathrm{HR}$ and electrolyte leakage assays and an $\mathrm{OD}_{600}$ of 0.3 for immunoprecipitation (IP) and immunoblotting assays and were incubated for $3 \mathrm{~h}$ at room temperature. For coexpression of multiple constructs, suspensions were mixed in equal ratios. Bacterial suspension mixtures were infiltrated by needleless syringe into expanding leaves of 3-week-old $N$. benthamiana. Leaves were sprayed with $50 \mu \mathrm{M}$ dexamethasone $45 \mathrm{~h}$ after injection to induce transgene expression. Samples were harvested $6 \mathrm{~h}$ after dexamethasone application for protein extraction, were flash-frozen in liquid nitrogen, and were stored at $-80^{\circ} \mathrm{C}$. HR was evaluated and leaves were photographed $24 \mathrm{~h}$ after dexamethasone application, using a high-intensity longwave (365 nm) UV lamp (Black-Ray B-100AP, UVP).

\section{Immunoblot analysis.}

Frozen $N$. benthamiana leaf tissue $(0.5 \mathrm{~g})$ was ground in two volumes of protein extraction buffer $(150 \mathrm{mM} \mathrm{NaCl}, 50 \mathrm{mM}$ Tris [pH 7.5], 0.1\% Nonidet P-40 [Sigma-Aldrich], 1\% plant protease inhibitor cocktail [Sigma-Aldrich], and 1\% 2,2'dipyridyl disulfide [Chem-Impex]), using a ceramic mortar and pestle, and were centrifuged at $10,000 \times g$ for $10 \mathrm{~min}$ at $4^{\circ} \mathrm{C}$ to pellet debris. Eighty microliters of total protein lysate were combined with $20 \mu$ of $5 \times$ sodium dodecyl sulfate (SDS) loading buffer, and the mixture was boiled at $95^{\circ} \mathrm{C}$ for $10 \mathrm{~min}$. All samples were loaded on 4 to $20 \%$ gradient Precise protein gels (Thermo Fisher Scientific) and were separated at $185 \mathrm{~V}$ for $1 \mathrm{~h}$ in $1 \times$ Tris/glycine/SDS running buffer. Total proteins were transferred to a nitrocellulose membrane (GE Water and Process Technologies). Ponceau staining was used to confirm equal loading of protein samples and successful transfer. Membranes were washed with $1 \times$ Tris-buffered saline $(50 \mathrm{mM}$ Tris- $\mathrm{HCl}, 150 \mathrm{mM} \mathrm{NaCl}, \mathrm{pH} 7.5)$ solution containing $0.1 \%$ Tween 20 (TBST) and were blocked with 5\% Difco skim milk (BD) overnight at $4^{\circ} \mathrm{C}$. Proteins were detected with $1: 5,000$ diluted peroxidase-conjugated anti-HA antibody (rat monoclonal; Roche) and a 1:5,000 diluted peroxidase-conjugated anti-c-Myc antibody (mouse monoclonal; Thermo Fisher Scientific) for $1 \mathrm{~h}$ and were washed three times for $10 \mathrm{~min}$ in TBST solution. Protein bands were imaged using Immuno-Star reagents (Bio-Rad) and X-ray film.

\section{Allele sequencing and expression analysis.}

DNA was isolated from ground frozen leaf tissue using the GeneJET Plant Genomic DNA purification kit (Thermo Scientific). Primers were designed throughout the genes of interest and fragments were amplified from genomic DNA using Q5 2X master mix (NEB), then, Sanger-sequenced at the Cornell Biotechnology Resource Center. RNA was isolated from the primary leaf of a 10-day-old plant, using the RNeasy plant mini kit (Qiagen), after freezing and grinding. RNA samples were quantified using a NanoDrop spectrophotometer (Thermo Scientific) and $500 \mathrm{ng}$ of RNA from each sample were used to make cDNA with SuperScript III reverse transcription (Invitrogen) and oligo dT primers. DreamTaq DNA polymerase (Thermo Scientific) was used for 30-cycle PCRs of $1 \mu \mathrm{l}$ of cDNA or $50 \mathrm{ng}$ of gDNA template. Eight microliters of the PCR products were then visualized in a $1 \%$ agarose gel. Samples chosen for expression and sequence analysis were chosen based on NAM population parent lines and to encompass two or more lines for all phenotypes.

\section{Electrolyte leakage assays in N. benthamiana.}

Electrolyte leakage assays were performed as described previously (Kim et al. 2016). In brief, after infiltration of Agrobacterium strains into $N$. benthamiana, leaf discs were collected from the infiltrated area using a cork borer $(5 \mathrm{~mm}$ diameter) $2 \mathrm{~h}$ post-dexamethasone application. Four leaf discs from four individual leaves of four different plants were included for each replication. The leaf discs were washed three times with distilled water and were floated in $5 \mathrm{ml}$ of distilled water supplemented with $0.001 \%$ Tween 20 (Sigma-Aldrich). Conductivity was monitored using a Traceable Pen conductivity meter (VWR) at the indicated timepoints after dexamethasone induction.

\section{Immunoprecipitation assay in $N$. benthamiana.}

Frozen $N$. benthamiana leaf tissue (four leaves) was ground in $1 \mathrm{ml}$ of IP buffer (50 mM Tris- $\mathrm{HCl}$ [pH 7.5], $150 \mathrm{mM} \mathrm{NaCl}$, $10 \%$ glycerol, $1 \mathrm{mM}$ dithiothreitol, $1 \mathrm{mM}$ EDTA, $1 \%$ NP40, $0.1 \%$ Triton $\mathrm{X}-100,1 \%$ plant protease inhibitor cocktail [Sigma-Aldrich], and 1\% 2,2'-dipyridyl disulfide [ChemImpex]), using a ceramic mortar and pestle, and gently rotated for $1 \mathrm{~h}$ at $4^{\circ} \mathrm{C}$. The samples were centrifuged at $10,000 \times g$ for $10 \mathrm{~min}$ at $4^{\circ} \mathrm{C}$ twice to remove plant debris. Then, $500 \mu \mathrm{l}$ of the clarified extract was incubated with $10 \mu \mathrm{l}$ of green fluorescent protein (GFP)-Trap A (Chromotek) $\alpha$-GFP bead slurry overnight at $4^{\circ} \mathrm{C}$ with constant end-over-end rotation. After overnight incubation, the $\alpha$-GFP beads were pelleted by centrifugation at $4,000 \times g$ for $1 \mathrm{~min}$ at $4^{\circ} \mathrm{C}$ and were washed five times with $500 \mu \mathrm{l}$ of IP wash buffer, $80 \mu \mathrm{l}$ of the immunocomplexes was resuspended in $20 \mu \mathrm{l}$ of $5 \times$ SDS loading buffer, and the mixture was boiled at $95^{\circ} \mathrm{C}$ for $10 \mathrm{~min}$. All protein samples were resolved on 4 to $20 \%$ gradient Precise protein gels (Thermo Scientific) and were separated at $185 \mathrm{~V}$ for $1 \mathrm{~h}$ 
in $1 \times$ Tris/glycine/SDS running buffer. Total proteins were transferred to a nitrocellulose membrane (GE Water and Process Technologies). Membranes were blocked with 5\% Difco skim milk (BD) overnight at $4^{\circ} \mathrm{C}$. Proteins were detected with 1:5,000 horseradish peroxidase-conjugated anti-HA antibody (rat monoclonal; Roche) or 1:5,000 monoclonal mouse anti-GFP antibody (Novus Biologicals), were washed in TBST overnight, and were incubated with 1:5,000 horseradish peroxidaseconjugated goat antimouse antibody (abcam). The nitrocellulose membranes were washed three times for $15 \mathrm{~min}$ in TBST solution and protein bands were imaged using Immuno-Star reagents (Bio-Rad) or Supersignal West Femto maximum sensitivity substrates (Thermo Scientific) and X-ray film.

\section{DAB assay for hydrogen peroxide accumulation in wheat.}

Hydrogen peroxide accumulation was detected following the protocol described by Liu et al. (2012) and Thordal-Christensen et al. (1997). In brief, $0.01 \mathrm{~g}$ of DAB powder (Sigma-Aldrich) was dissolved in $10 \mathrm{ml}$ of distilled water $(\mathrm{pH} \mathrm{3.6)}$ and was incubated at $37^{\circ} \mathrm{C}$ for $1 \mathrm{~h}$, on a New Brunswick orbital shaker, to dissolve the DAB powder. Wheat leaf segments were harvested from the infiltrated leaves 3 days postinoculation, (10 plants per treatment, experiment performed twice), were immersed immediately in DAB solution and were vacuum infiltrated for $10 \mathrm{~s}$. The samples were wrapped in aluminum foil and were incubated overnight in the dark. After overnight incubation, the stained leaf tissue was gently rinsed with distilled water, was submerged in $70 \%$ ethanol, and was incubated at $70^{\circ} \mathrm{C}$ to clear the chlorophyll. The cleared leaves were rinsed and stored in a lactic acid/glycerol/ $\mathrm{H}_{2} \mathrm{O}$ solution $(1: 1: 1$, $\mathrm{vol} / \mathrm{vol} / \mathrm{vol}$ ) for photography. Wheat leaves inoculated with $10 \mathrm{mM} \mathrm{MgCl}{ }_{2}$ (mock) or $P$. syringae DC3000(D36E) expressing $\mathrm{AvrPphB}(\mathrm{C} 98 \mathrm{~S})$ were used as controls.

\section{ACKNOWLEDGMENTS}

The authors thank A. Ollhoff, A. M. Poets, G. Muehlbauer, and K. Smith at the University of Minnesota, St. Paul, for pre-publication access to Rasmusson spring NAM populations and associated SNP marker data and maps; P. Tyagi and G. Brown-Guedira, USDA-Agricultural Research Service, Raleigh, NC, for generating GBS marker data; A. Collmer and H.-L. Wei, Cornell University, for Pseudomonas syringae DC3000(D36E); G. Fuerst, USDA-ARS, Corn Insects and Crop Genetics Research Unit, Iowa State University, Ames, for generation, maintenance, and distribution of barley germplasm; and H. Z. Karimi and L. Joseph, Indiana University, Bloomington, for technical assistance; and the USDA Wheat Germplasm Collection and S. Hulbert, Washington State University, Pullman, for wheat seed.

\section{LITERATURE CITED}

Adams, M. J., Antoniw, J. F., and Beaudoin, F. 2005. Overview and analysis of the polyprotein cleavage sites in the family Potyviridae. Mol. Plant Pathol. 6:471-487.

Ade, J., DeYoung, B. J., Golstein, C., and Innes, R. W. 2007. Indirect activation of a plant nucleotide binding site-leucine-rich repeat protein by a bacterial protease. Proc. Natl. Acad. Sci. U.S.A. 104:2531-2536.

Afzal, A. J., Kim, J. H., and Mackey, D. 2013. The role of NOI-domain containing proteins in plant immune signaling. BMC Genomics 14:327.

Antonino de Souza Júnior, J. D., Ramos Coelho, R., Tristan Lourenço, I., da Rocha Fragoso, R., Barbosa Viana, A. A., Lima Pepino de Macedo, L., Mattar da Silva, M. C., Gomes Carneiro, R. M., Engler, G., de AlmeidaEngler, J., and Grossi-de-Sa, M. F. 2013. Knocking-down Meloidogyne incognita proteases by plant-delivered dsRNA has negative pleiotropic effect on nematode vigor. PLoS One 8:e85364.

Aoyama, T., and Chua, N. H. 1997. A glucocorticoid-mediated transcriptional induction system in transgenic plants. Plant J. 11:605-612.

Ashfield, T., Ong, L. E., Nobuta, K., Schneider, C. M., and Innes, R. W. 2004. Convergent evolution of disease resistance gene specificity in two flowering plant families. Plant Cell 16:309-318.

Ashfield, T., Redditt, T., Russell, A., Kessens, R., Rodibaugh, N., Galloway, L., Kang, Q., Podicheti, R., and Innes, R. W. 2014. Evolutionary relationship of disease resistance genes in soybean and Arabidopsis specific for the Pseudomonas syringae effectors AvrB and AvrRpm1. Plant Physiol. 166:235-251.

Bombarely, A., Rosli, H. G., Vrebalov, J., Moffett, P., Mueller, L. A., and Martin, G. B. 2012. A draft genome sequence of Nicotiana benthamiana to enhance molecular plant-microbe biology research. Mol. PlantMicrobe Interact. 25:1523-1530.

Brunner, S., Hurni, S., Streckeisen, P., Mayr, G., Albrecht, M., Yahiaoui, N., and Keller, B. 2010. Intragenic allele pyramiding combines different specificities of wheat Pm3 resistance alleles. Plant J. 64:433-445.

Caldwell, K. S., and Michelmore, R. W. 2009. Arabidopsis thaliana genes encoding defense signaling and recognition proteins exhibit contrasting evolutionary dynamics. Genetics 181:671-684.

Choi, I.-R., Stenger, D. C., Morris, T. J., and French, R. 2000. A plant virus vector for systemic expression of foreign genes in cereals. Plant J. 23: 547-555.

Clavijo, B. J., Venturini, L., Schudoma, C., Accinelli, G. G., Kaithakottil, G., Wright, J., Borrill, P., Kettleborough, G., Heavens, D., Chapman, H., Lipscombe, J., Barker, T., Lu, F. H., McKenzie, N., Raats, D., RamirezGonzalez, R. H., Coince, A., Peel, N., Percival-Alwyn, L., Duncan, O., Trösch, J., Yu, G., Bolser, D. M., Namaati, G., Kerhornou, A., Spannagl, M., Gundlach, H., Haberer, G., Davey, R. P., Fosker, C., Palma, F. D., Phillips, A. L., Millar, A. H., Kersey, P. J., Uauy, C., Krasileva, K. V., Swarbreck, D., Bevan, M. W., and Clark, M. D. 2017. An improved assembly and annotation of the allohexaploid wheat genome identifies complete families of agronomic genes and provides genomic evidence for chromosomal translocations. Genome Res. 27:885-896.

Coll, N. S., Epple, P., and Dangl, J. L. 2011. Programmed cell death in the plant immune system. Cell Death Differ. 18:1247-1256.

Collier, S. M., Hamel, L. P., and Moffett, P. 2011. Cell death mediated by the N-terminal domains of a unique and highly conserved class of NBLRR protein. Mol. Plant-Microbe Interact. 24:918-931.

Cutler, S. R., Ehrhardt, D. W., Griffitts, J. S., and Somerville, C. R. 2000. Random GFP:cDNA fusions enable visualization of subcellular structures in cells of Arabidopsis at a high frequency. Proc. Natl. Acad. Sci. U.S.A. 97:3718-3723.

Dean, P. 2011. Functional domains and motifs of bacterial type III effector proteins and their roles in infection. FEMS Microbiol. Rev. 35: 1100-1125

DeYoung, B. J., Qi, D., Kim, S.-H., Burke, T. P., and Innes, R. W. 2012. Activation of a plant nucleotide binding-leucine rich repeat disease resistance protein by a modified self protein. Cell. Microbiol. 14: 1071-1084.

Dowen, R. H., Engel, J. L., Shao, F., Ecker, J. R., and Dixon, J. E. 2009. A family of bacterial cysteine protease type III effectors utilizes acylationdependent and -independent strategies to localize to plasma membranes. J. Biol. Chem. 284:15867-15879.

Farnham, G., and Baulcombe, D. C. 2006. Artificial evolution extends the spectrum of viruses that are targeted by a disease-resistance gene from potato. Proc. Natl. Acad. Sci. U.S.A. 103:18828-18833.

Feng, F., Yang, F., Rong, W., Wu, X., Zhang, J., Chen, S., He, C., and Zhou, J.-M. 2012. A Xanthomonas uridine 5'-monophosphate transferase inhibits plant immune kinases. Nature 485:114-118.

Harris, C. J., Slootweg, E. J., Goverse, A., and Baulcombe, D. C. 2013. Stepwise artificial evolution of a plant disease resistance gene. Proc. Natl. Acad. Sci. U.S.A. 110:21189-21194.

Huang, C.-L., Hwang, S.-Y., Chiang, Y.-C., and Lin, T.-P. 2008. Molecular evolution of the Pi-ta gene resistant to rice blast in wild rice (Oryza rufipogon). Genetics 179:1527-1538.

Jacob, F., Vernaldi, S., and Maekawa, T. 2013. Evolution and conservation of plant NLR functions. Front. Immunol. 4:297.

Jashni, M. K., Mehrabi, R., Collemare, J., Mesarich, C. H., and de Wit, P. J. G. M. 2015. The battle in the apoplast: Further insights into the roles of proteases and their inhibitors in plant-pathogen interactions. Front. Plant Sci. 6:584.

Jenner, C., Hitchin, E., Mansfield, J., Walters, K., Betteridge, P., Teverson, D., and Taylor, J. 1991. Gene-for-gene interactions between Pseudomonas syringae pv. phaseolicola and Phaseolus. Mol. Plant-Microbe Interact. 4:553-562.

Jones, J. D. G., and Dangl, J. L. 2006. The plant immune system. Nature 444:323-329.

Karasov, T. L., Kniskern, J. M., Gao, L., DeYoung, B. J., Ding, J., Dubiella, U., Lastra, R. O., Nallu, S., Roux, F., Innes, R. W., Barrett, L. G., Hudson, R. R., and Bergelson, J. 2014. The long-term maintenance of a resistance polymorphism through diffuse interactions. Nature 512: 436-440.

Kersey, P. J., Allen, J. E., Allot, A., Barba, M., Boddu, S., Bolt, B. J., Carvalho-Silva, D., Christensen, M., Davis, P., Grabmueller, C., Kumar, 
N., Liu, Z., Maurel, T., Moore, B., McDowall, M. D., Maheswari, U., Naamati, G., Newman, V., Ong, C. K., Paulini, M., Pedro, H., Perry, E., Russell, M., Sparrow, H., Tapanari, E., Taylor, K., Vullo, A., Williams, G., Zadissia, A., Olson, A., Stein, J., Wei, S., Tello-Ruiz, M., Ware, D., Luciani, A., Potter, S., Finn, R. D., Urban, M., Hammond-Kosack, K. E., Bolser, D. M., De Silva, N., Howe, K. L., Langridge, N., Maslen, G., Staines, D. M., and Yates, A. 2018. Ensembl genomes 2018: An integrated omics infrastructure for non-vertebrate species. Nucleic Acids Res. 46:D802-D808.

Kim, S. H., Qi, D., Ashfield, T., Helm, M., and Innes, R. W. 2016. Using decoys to expand the recognition specificity of a plant disease resistance protein. Science 351:684-687.

Klement, Z. and Goodman, R. N. 1967. The hypersensitive reaction to infection by bacterial plant pathogens. Annu. Rev. Phytopathol. 5:17-44.

Kumar, S., Stecher, G., and Tamura, K. 2016. MEGA7: Molecular evolutionary genetics analysis version 7.0 for bigger datasets. Mol. Biol. Evol. 33:1870-1874.

Liu, Z., Zhang, Z., Faris, J. D., Oliver, R. P., Syme, R., McDonald, M. C., McDonald, B. A., Solomon, P. S., Lu, S., Shelver, W. L., Xu, S., and Friesen, T. L. 2012. The cysteine rich necrotrophic effector SnTox1 produced by Stagonospora nodorum triggers susceptibility of wheat lines harboring Snn1. PLoS Pathog. 8:e1002467.

Lu, X., Kracher, B., Saur, I. M. L., Bauer, S., Ellwood, S. R., Wise, R., Yaeno, T., Maekawa, T., and Schulze-Lefert, P. 2016. Allelic barley MLA immune receptors recognize sequence-unrelated avirulence effectors of the powdery mildew pathogen. Proc. Natl. Acad. Sci. U.S.A. 113:E6486-E6495.

Marchler-Bauer, A., and Bryant, S. H. 2004. CD-Search: Protein domain annotations on the fly. Nucleic Acids Res. 32:W327-W331.

Mascher, M., Gundlach, H., Himmelbach, A., Beier, S., Twardziok, S. O., Wicker, T., Radchuk, V., Dockter, C., Hedley, P. E., Russell, J., Bayer, M., Ramsay, L., Liu, H., Haberer, G., Zhang, X.-Q., Zhang, Q., Barrero, R. A., Li, L., Taudien, S., Groth, M., Felder, M., Hastie, A., Šimková, H., Staňková, H., Vrána, J., Chan, S., Muñoz-Amatriaín, M., Ounit, R., Wanamaker, S., Bolser, D., Colmsee, C., Schmutzer, T., AliyevaSchnorr, L., Grasso, S., Tanskanen, J., Chailyan, A., Sampath, D., Heavens, D., Clissold, L., Cao, S., Chapman, B., Dai, F., Han, Y., Li, H., Li, X., Lin, C., McCooke, J. K., Tan, C., Wang, P., Wang, S., Yin, S., Zhou, G., Poland, J. A., Bellgard, M. I., Borisjuk, L., Houben, A., Doležel, J., Ayling, S., Lonardi, S., Kersey, P., Langridge, P., Muehlbauer, G. J., Clark, M. D., Caccamo, M., Schulman, A. H., Mayer, K. F. X., Platzer, M., Close, T. J., Scholz, U., Hansson, M., Zhang, G., Braumann, I., Spannagl, M., Li, C., Waugh, R., and Stein, N. 2017. A chromosome conformation capture ordered sequence of the barley genome. Nature 544:427-433.

Nice, L. M., Steffenson, B. J., Brown-Guedira, G. L., Akhunov, E. D., Liu, C., Kono, T. J. Y., Morrell, P. L., Blake, T. K., Horsley, R. D., Smith, K. P., and Muehlbauer, G. J. 2016. Development and genetic characterization of an advanced backcross-nested association mapping $(\mathrm{AB}-\mathrm{NAM})$ population of wild $\times$ cultivated barley. Genetics 203: 1453-1467.

Pliego, C., Nowara, D., Bonciani, G., Gheorghe, D. M., Xu, R., Surana, P., Whigham, E., Nettleton, D., Bogdanove, A. J., Wise, R. P., Schweizer, P., Bindschedler, L. V., and Spanu, P. D. 2013. Host-induced gene silencing in barley powdery mildew reveals a class of ribonuclease-like effectors. Mol. Plant-Microbe Interact. 26:633-642.

Qi, D., DeYoung, B. J., and Innes, R. W. 2012. Structure-function analysis of the coiled-coil and leucine-rich repeat domains of the RPS5 disease resistance protein. Plant Physiol. 158:1819-1832.

Qi, D., Dubiella, U., Kim, S. H., Sloss, D. I., Dowen, R. H., Dixon, J. E., and Innes, R. W. 2014. Recognition of the protein kinase AVRPPHB SUSCEPTIBLE1 by the disease resistance protein RESISTANCE TO PSEUDOMONAS SYRINGAE5 is dependent on s-acylation and an exposed loop in AVRPPHB SUSCEPTIBLE1. Plant Physiol. 164: 340-351.

Ren, J., Wen, L., Gao, X., Jin, C., Xue, Y., and Yao, X. 2008. CSS-Palm 2.0: An updated software for palmitoylation sites prediction. Protein Eng. Des. Sel. 21:639-644.

Ronquist, F., Teslenko, M., van der Mark, P., Ayres, D. L., Darling, A., Höhna, S., Larget, B., Liu, L., Suchard, M. A., and Huelsenbeck, J. P. 2012. MrBayes 3.2: Efficient Bayesian phylogenetic inference and model choice across a large model space. Syst. Biol. 61: 539-542.

Russell, A. R., Ashfield, T., and Innes, R. W. 2015. Pseudomonas syringae effector AvrPphB suppresses AvrB-induced activation of RPM1 but not AvrRpm1-induced activation. Mol. Plant-Microbe Interact. 28:727-735.

Segretin, M. E., Pais, M., Franceschetti, M., Chaparro-Garcia, A., Bos, J. I. B., Banfield, M. J., and Kamoun, S. 2014. Single amino acid mutations in the potato immune receptor R3a expand response to Phytophthora effectors. Mol. Plant-Microbe Interact. 27:624-637.

Selote, D., and Kachroo, A. 2010. RPG1-B-derived resistance to AvrBexpressing Pseudomonas syringae requires RIN4-like proteins in soybean. Plant Physiol. 153:1199-1211.

Shan, L., He, P., Li, J., Heese, A., Peck, S. C., Nürnberger, T., Martin, G. B., and Sheen, J. 2008. Bacterial effectors target the common signaling partner BAK1 to disrupt multiple MAMP receptor-signaling complexes and impede plant immunity. Cell Host Microbe 4:17-27.

Shao, F., Golstein, C., Ade, J., Stoutemyer, M., Dixon, J. E., and Innes, R. W. 2003. Cleavage of Arabidopsis PBS1 by a bacterial type III effector. Science 301:1230-1233.

Shao, F., Merritt, P. M., Bao, Z., Innes, R. W., and Dixon, J. E. 2002. A Yersinia effector and a Pseudomonas avirulence protein define a family of cysteine proteases functioning in bacterial pathogenesis. Cell 109. 575-588.

Sievers, F., Wilm, A., Dineen, D., Gibson, T.J., Karplus, K., Li, W., Lopez, R., McWilliam, H., Remmert, M., Söding, J., Thompson, J.D., and Higgins, D.G. 2011.Fast, scalable generation of high-quality protein multiple sequence alignments using Clustal Omega. Mol. Syst. Biol. 7: 539.

Simonich, M. T., and Innes, R. W. 1995. A disease resistance gene in Arabidopsis with specificity for the avrPph3 gene of Pseudomonas syringae pv. phaseolicola. Mol. Plant-Microbe Interact. 8: 637-640.

Singh, K., Wegulo, S. N., Skoracka, A., and Kundu, J. K. 2018. Wheat streak mosaic virus: A century old virus with rising importance worldwide. Mol. Plant Pathol. 19:2193-2206.

Smith, J. J., and Mansfield, J. W. 1981. Interactions between pseudomonads and leaves of oats, wheat and barley. Physiol. Plant Pathol. 18: 345-356.

Steuernagel, B., Jupe, F., Witek, K., Jones, J. D., and Wulff, B. B. 2015. NLR-parser: Rapid annotation of plant NLR complements. Bioinformatics 31:1665-1667.

Stirnweis, D., Milani, S. D., Jordan, T., Keller, B., and Brunner, S. 2014. Substitutions of two amino acids in the nucleotide-binding site domain of a resistance protein enhance the hypersensitive response and enlarge the PM3F resistance spectrum in wheat. Mol. Plant-Microbe Interact. 27: 265-276.

Sun, J., Huang, G., Fan, F., Wang, S., Zhang, Y., Han, Y., Zou, Y., and Lu, D. 2017. Comparative study of Arabidopsis PBS1 and a wheat PBS1 homolog helps understand the mechanism of PBS1 functioning in innate immunity. Sci. Rep. 7:5487.

Tatineni, S., McMechan, A. J., Hein, G. L., and French, R. 2011. Efficient and stable expression of GFP through Wheat streak mosaic virus-based vectors in cereal hosts using a range of cleavage sites: Formation of dense fluorescent aggregates for sensitive virus tracking. Virology 410: 268-281.

Thordal-Christensen, H., Zhang, Z., Wei, Y., and Collinge, D. B. 1997. Subcellular localization of $\mathrm{H}_{2} \mathrm{O}_{2}$ in plants. $\mathrm{H}_{2} \mathrm{O}_{2}$ accumulation in papillae and hypersensitive response during the barley-powdery mildew interaction. Plant J. 11:1187-1194.

Tian, D., Araki, H., Stahl, E., Bergelson, J., and Kreitman, M. 2002 Signature of balancing selection in Arabidopsis. Proc. Natl. Acad. Sci. U. S.A. 99:11525-11530.

Vinatzer, B. A., Teitzel, G. M., Lee, M.-W., Jelenska, J., Hotton, S., Fairfax, K., Jenrette, J., and Greenberg, J. T. 2006. The type III effector repertoire of Pseudomonas syringae pv. syringae $\mathrm{B} 728 \mathrm{a}$ and its role in survival and disease on host and non-host plants. Mol. Microbiol. 62: 26-44.

Wang, G., Roux, B., Feng, F., Guy, E., Li, L., Li, N., Zhang, X., Lautier, M., Jardinaud, M.-F., Chabannes, M., Arlat, M., Chen, S., He, C., Noël, L. D., and Zhou, J. M. 2015. The decoy substrate of a pathogen effector and a pseudokinase specify pathogen-induced modified-self recognition and immunity in plants. Cell Host Microbe 18:285-295.

Wei, H.-L., Chakravarthy, S., Mathieu, J., Helmann, T. C., Stodghill, P., Swingle, B., Martin, G. B., and Collmer, A. 2015. Pseudomonas syringae pv. tomato DC3000 type III secretion effector polymutants reveal an interplay between HopAD1 and AvrPtoB. Cell Host Microbe 17:752-762.

Whigham, E., Qi, S., Mistry, D., Surana, P., Xu, R., Fuerst, G., Pliego, C., Bindschedler, L. V., Spanu, P. D., Dickerson, J. A., Innes, R. W., Nettleton, D., Bogdanove, A. J., and Wise, R. P. 2015. Broadly conserved fungal effector BEC1019 suppresses host cell death and enhances pathogen virulence in powdery mildew of barley (Hordeum vulgare L.). Mol. Plant-Microbe Interact. 28:968-983.

Xavier, A., Xu, S., Muir, W. M., and Rainey, K. M. 2015. NAM: Association studies in multiple populations. Bioinformatics 31:3862-3864. 
Xia, Y. 2004. Proteases in pathogenesis and plant defence. Cell. Microbiol. 6:905-913.

Yamaguchi, K., Yamada, K., and Kawasaki, T. 2013. Receptor-like cytoplasmic kinases are pivotal components in pattern recognition receptor-mediated signaling in plant immunity. Plant Signal. Behav. 8:4161, 25662.

Yin, C., and Hulbert, S. 2010. Prospects for functional analysis of effectors from cereal rust fungi. Euphytica 179:57-67.

Zhang, J., Li, W., Xiang, T., Liu, Z., Laluk, K., Ding, X., Zou, Y., Gao, M., Zhang, X., Chen, S., Mengiste, T., Zhang, Y., and Zhou, J.-M. 2010. Receptor-like cytoplasmic kinases integrate signaling from multiple plant immune receptors and are targeted by a Pseudomonas syringae effector. Cell Host Microbe 7:290-301.

\section{AUTHOR-RECOMMENDED INTERNET RESOURCES}

CSS-PALM 4.0 website: http://csspalm.biocuckoo.org figshare: https://figshare.com

National Plant Germplasm System web portal: https://www.ars-grin.gov/npgs 